\title{
Effect of Blade Outlet Angle on Unsteady Hydrodynamic Force of Closed-Type Centrifugal Pump with Single Blade
}

\author{
Yasuyuki Nishi' ${ }^{1}$ and Junichiro Fukutomi ${ }^{2}$ \\ ${ }^{1}$ Department of Mechanical Engineering, Ibaraki University, 4-12-1 Nakanarusawa-cho, Hitachi-shi, Ibaraki 316-8511, Japan \\ ${ }^{2}$ Institute of Technology and Science, The University of Tokushima, 2-1 Minamijosanjima-cho, Tokushima-shi, \\ Tokushima 770-8506, Japan \\ Correspondence should be addressed to Yasuyuki Nishi; y-nishi@mx.ibaraki.ac.jp
}

Received 8 August 2014; Accepted 9 October 2014; Published 18 November 2014

Academic Editor: Ningsheng Feng

Copyright (C) 2014 Y. Nishi and J. Fukutomi. This is an open access article distributed under the Creative Commons Attribution License, which permits unrestricted use, distribution, and reproduction in any medium, provided the original work is properly cited.

Geometrically, the single-blade centrifugal impeller, commonly used today as a sewage pump, is not axially symmetric. For this reason, the static pressure around the impeller fluctuates greatly when the impeller is rotating, and not only the radial thrust but also the axial thrust shows large fluctuations. Therefore, it is extremely important for the improvement of pump reliability to quantitatively grasp these fluctuating hydrodynamic forces. In this study, we investigated the unsteady hydrodynamic forces in a closed-type centrifugal pump with a single blade for different blade outlet angles using a numerical analysis that takes into account both experiment and the leakage flow. The results clearly showed the effect of the blade outlet angle on that act on the impeller. The root-mean-square value of the fluctuating component of the total radial thrust was roughly the same for whichever impeller at low flow rate, but at high flow rates, the value increased for impellers with larger blade outlet angles. Moreover, when the leakage flow rate increased with increasing static pressure around the impeller, such that the rear and front shroud parts were subject to high pressure, the absolute value of the axial thrust on both these parts increased.

\section{Introduction}

Because a sewage pump is used for the transfer of liquids containing foreign bodies, such as solid and fibrous material, it must not only be highly efficient but also allow the easy passage of foreign bodies. The passed particle size relative to the pump bore (the minimum particle size in the flow path inside the pump) exists as an index of the ease with which these foreign bodies can pass through [1]. It therefore follows that the single-blade centrifugal pump, consisting of just a single blade of broad blade width, has been widely used for this type of pump so that a large passed particle size is formed. Nevertheless, even for centrifugal pumps with many blades, geometrical manufacturing errors cause disproportional fluid force [2]. In contrast, with the single-blade centrifugal pump, by its very nature, the impeller itself is not axially symmetric from a geometrical viewpoint. Additionally, because a volute casing is installed on the outside of the impeller that is not axially symmetric, the static pressure distribution surrounding the impeller is extremely nonuniform, and an excessively fluctuating radial thrust acts on the impeller $[3,4]$. Because such excessively fluctuating radial thrust can lead to a drop in the axial strength, a shortening of the lifetime of the bearings and shaft sealing equipment, and the generation of axial vibrations, elucidating the generation mechanism behind this has become an important challenge.

Regarding the radial thrust in single-blade centrifugal pumps, such subjects have been investigated as the effect of the number of blades $[3,5]$, winding angle of the blade [3], distribution of the blade angle [6] and its relationship with the static pressure between the blades [4], effect of the casing shape $[3,6]$, effectiveness of adding extra mass $[4,7]$, and relationship to vibration of the casing [7]. In addition, the relationship between the hydrodynamic forces acting on the impeller and the whirling of the impeller has been investigated $[5,8-10]$. We have also proposed a design method for 


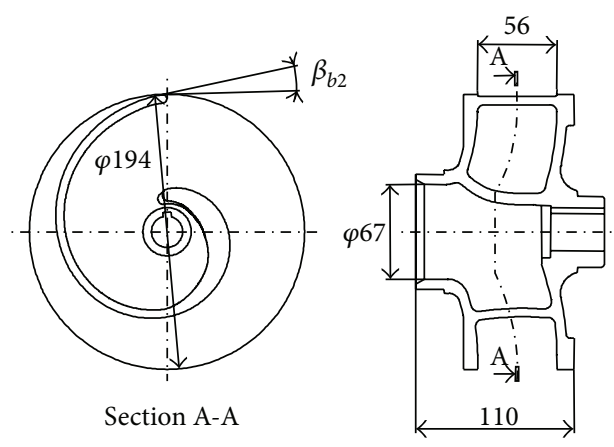

FIgURE 1: Test impeller.

single-blade centrifugal impellers and have discovered, for a closed-type centrifugal impeller with a single blade that was designed using this design method as a basis, how the performance characteristics relate to the radial thrust [11]. While modeling the components of the radial thrust using an unsteady conservation-of-momentum law to illustrate their behavior [12], we also explained how they were affected by the blade outlet angle [13]. However, hardly any research has been made on the axial thrust. In our previous studies, the hydrodynamic forces acting on the rear and front shroud parts were neglected in the numerical analyses. Accordingly, by performing a numerical analysis that takes into account the leakage flow on the rear surface of the rear and front shroud parts, we were able to demonstrate that not only did the radial thrust fluctuate with fluctuations in the static pressure distribution around the impeller but also the axial thrust fluctuated greatly [14]. Furthermore, modeling the components of the axial thrust, we showed how they behaved [15].

In this study, we implemented a numerical analysis that takes into account the leakage flow on the rear surface of the rear and front shroud parts of a closed-type single-blade centrifugal pump for different blade outlet angles. And with a comparative investigation, we could clarify how the blade outlet angle affects both the radial and axial thrust in the closed-type single-blade centrifugal pump.

\section{Experimental Apparatus and Method}

In this study, we used three types of single-blade centrifugal impellers with respective blade outlet angles $\beta_{b 2}$ of $8^{\circ}, 16^{\circ}$, and $24^{\circ}$. However, in the experiments, we used only impellers with $\beta_{b 2}=8$ and $\beta_{b 2}=16$. An overview of the test impeller $\left(\beta_{b 2}\right.$ $=8$ ) is shown in Figure 1, and its specifications are given in Table 1. An overview of the test pump is also given in Figure 2. The impeller with $\beta_{b 2}=8$ had a passed particle size of $56 \mathrm{~mm}$ and had been designed on the basis of the design method reported previously [11]. This design method stipulates the passed particle size beforehand, and the impeller design is implemented using, as design parameters, first, the relative velocity ratio of the blade inlet and blade outlet and, second, the absolute velocity ratio of the impeller suction inlet and the blade inlet. The impellers with $\beta_{b 2}=16$ and $\beta_{b 2}=24$ have
TABLE 1: Specifications of test impellers.

\begin{tabular}{lc}
\hline Impeller suction diameter $D_{0}$ & $67 \mathrm{~mm}$ \\
Impeller inner diameter $D_{1}$ & $58 \mathrm{~mm}$ \\
Impeller outer diameter $D_{2}$ & $194 \mathrm{~mm}$ \\
Blade inlet width $b_{1}$ & $56 \mathrm{~mm}$ \\
Blade outlet width $b_{2}$ & $56 \mathrm{~mm}$ \\
Blade inlet angle $\beta_{b 1}$ & $13^{\circ}$ \\
Blade outlet angle $\beta_{b 2}$ & $16^{\circ}$ \\
\hline
\end{tabular}

meridian planes that are equivalent to that for the impeller with $\beta_{b 2}=8$, and, as shown in Table 1 , only the blade outlet angle is varied. This pump has three narrow gaps between the impeller and the casing, as seen in Figure 2. These are the liner-ring gap (the gap with the casing wearing ring), the gap with the rear shroud part, and the gap with the front shroud part. The gap widths are, respectively, $0.75,0.5$, and $0.5 \mathrm{~mm}$ and the corresponding gap lengths are 17, 10.1, and $10.5 \mathrm{~mm}$. It should be noted that, because a mechanical tool has been adopted for the shaft sealing equipment in this pump, almost no leakage to the exterior occurs on the rear shroud part side.

Figure 3 gives an overview of the experimental apparatus. The experiment was conducted at a rotational speed of $n=$ $1740 \mathrm{~min}^{-1}$, and the flow rate $Q$ was adjusted with the gate valve mounted on the discharge side and measured using an electromagnetic flow rate meter. The total head $H$ was found from the static pressure measured before and after the pump with a strain-gauge-type pressure transducer and flow rate. The shaft power $L$ was found by measuring the rotational speed $n$ and torque $T$ with a magnetoelectric-type rotation detector and torque detector, respectively.

The coordinate system is defined by the $x-, y$-, and $z$ axes, as shown in Figure 2. The blade phase angle $\theta_{0}$ is taken in the anticlockwise direction from the $x$-axis, and the point where the end of the blade outlet passes through the $x$-axis is assumed as $\theta_{0}=0^{\circ}$ (the position shown in Figure 2). Eight monitor points were provided on the wall surface on the side of the front shroud part at positions $10 \mathrm{~mm}$ radially outwards from the impeller outlet in an anticlockwise direction from the $x$-axis as $\theta=0^{\circ}$. The pressure measurement was synchronized with the rotation of the impeller using the torque signal for the $\theta_{0}=0^{\circ}$ position of the end of the blade outlet as a reference.

For the radial thrust measurement, an $X-Y$ load cell was incorporated in the periphery of the bearings, as shown in Figures 4 and 5, and it was synchronized with the rotation of the impeller in the same way as that for the pressure measurement [11-15]. The "four-active-gauge" method was used for the $X-Y$ load cell by attaching the connected strain gauges together. The dynamic calibration method [16] was adopted for calibration. The relationship between the output voltage and the force was tested in air for a known centrifugal force acting on a calibrating circular plate, which has a mass found by subtracting from the impeller mass; that mass corresponds to the buoyancy force that normally acts on it. 


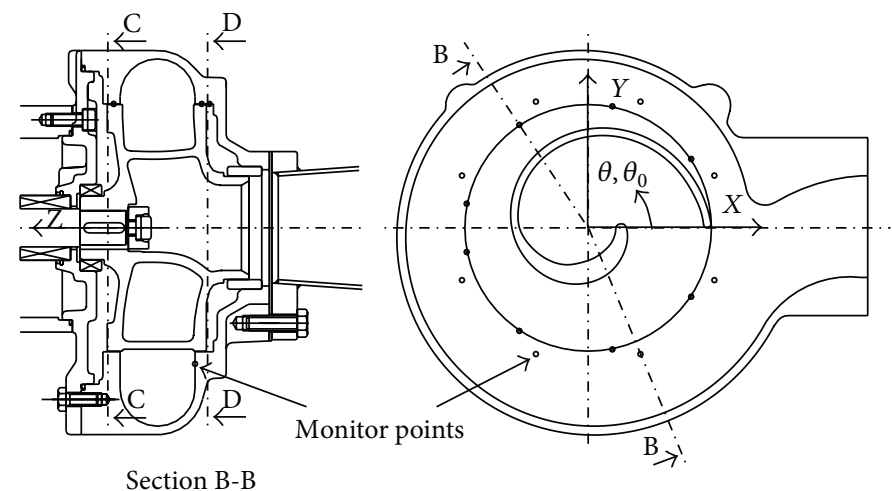

FIgURE 2: Test pump.

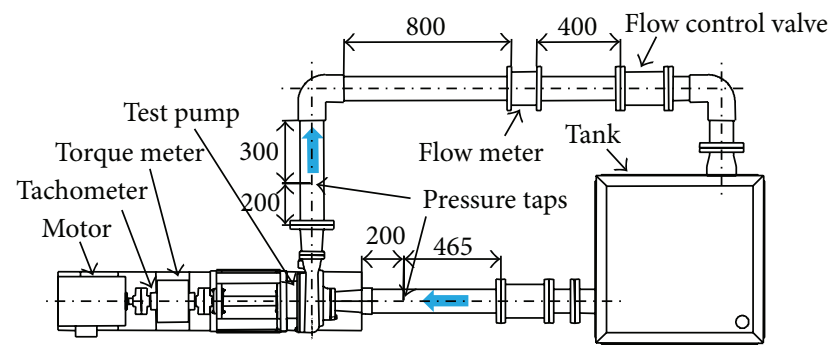

FIGURE 3: Experimental apparatus.

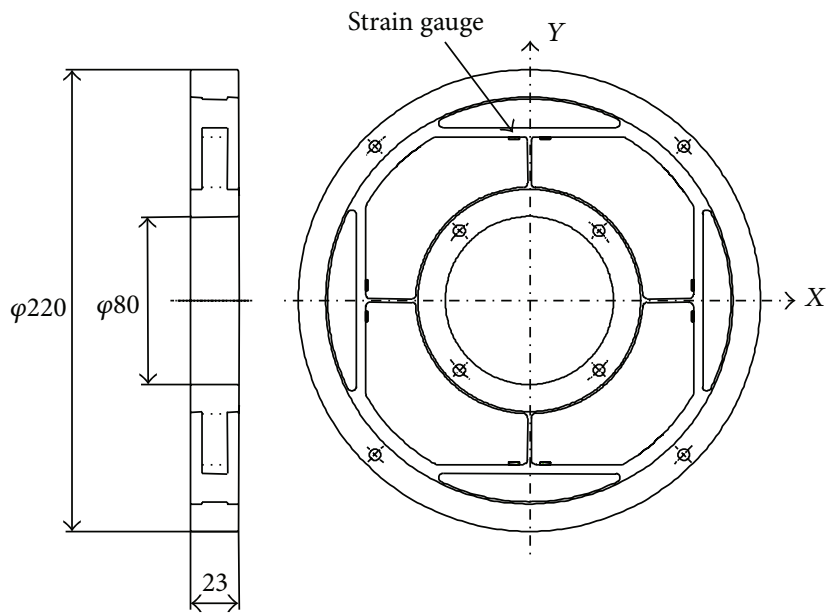

Figure 4: $X-Y$ load cell.

The calibration curves for the $X$ - and $Y$-directions when the force acts in the $Y$-direction are shown in Figure 6. The output voltage and the force are proportionally related. Moreover, when the force acts in the $Y$-direction, its influence on the $X$-direction is small. It should be noted that the dynamic balance was taken between the impeller under test and calibrating circular plate. The effect of the heat from the bearings was eliminated using a method where the pump was stopped over a short interval of around $15 \mathrm{~s}$ under thermally

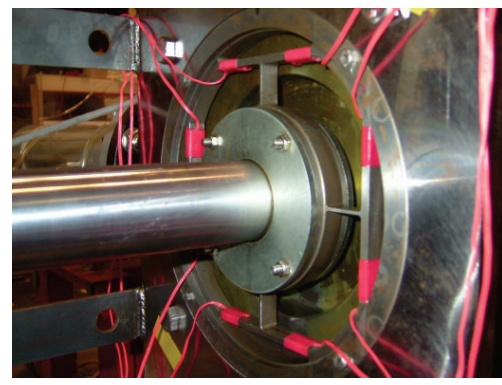

FigURE 5: $X-Y$ load cell incorporated in periphery of bearings.

stable conditions and was operated immediately afterwards, adjusting the zero point to take measurements under the same conditions.

\section{Numerical Analysis Method}

For the numerical analysis, we performed a three-dimensional unsteady-flow analysis using the general-purpose thermofluid analysis code ANSYS CFX13.0. Reynolds-averaged Navier-Stokes equations were used as a basis, and the SST (shear stress transport) model was used to model the turbulent flow.

The computational domain and computational grid for the pump part are shown, respectively, in Figures 7(a) and 7(b). This study differs from past research [11-13] in that the gaps between the outer surfaces of the rear and front shroud parts of the impeller and the casing are actually modeled. The computation domain consists of the suction pipe, impeller, volute casing, regions in the gaps with the rear and front shroud parts, and discharge pipe. The computational grids for the impellers with $\beta_{b 2}=8, \beta_{b 2}=16$, and $\beta_{b 2}=24$ have 690,000 , 705,000 , and 707,000 elements, respectively, where the total number of elements in the grids is 2,328,000, 2,343,000, and $2,345,000$, respectively. Here, the computational grids for the suction pipe, volute casing, regions in the gaps with the rear and front shroud parts, and the discharge pipe are identical in all cases, with, respectively, 149,000, $462,000,340,000,572,000$, and 115,000 elements. The number 


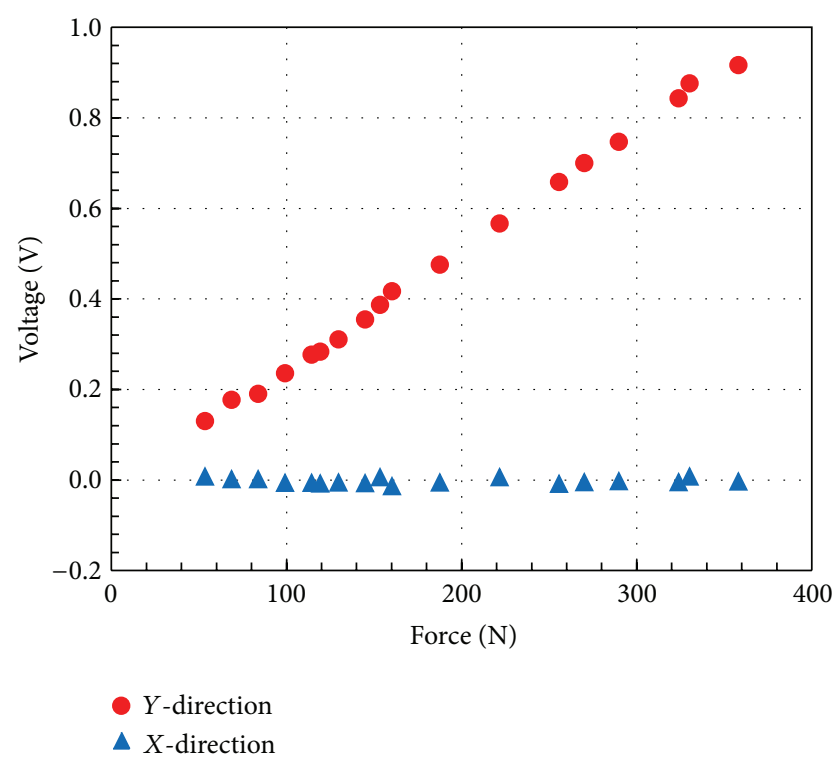

FIGURE 6: Calibration curves for $X$ - and $Y$-directions when force acts in the $Y$-direction.

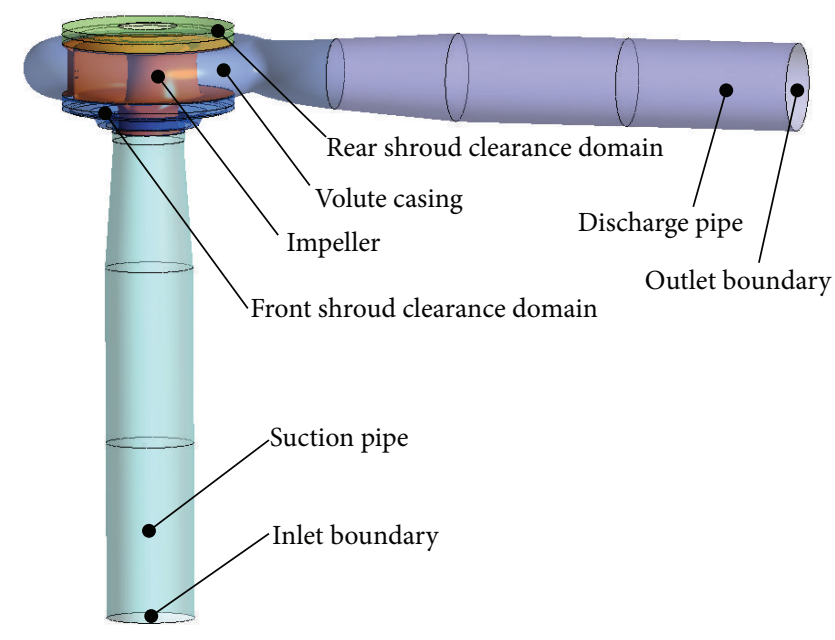

(a) Computational domain

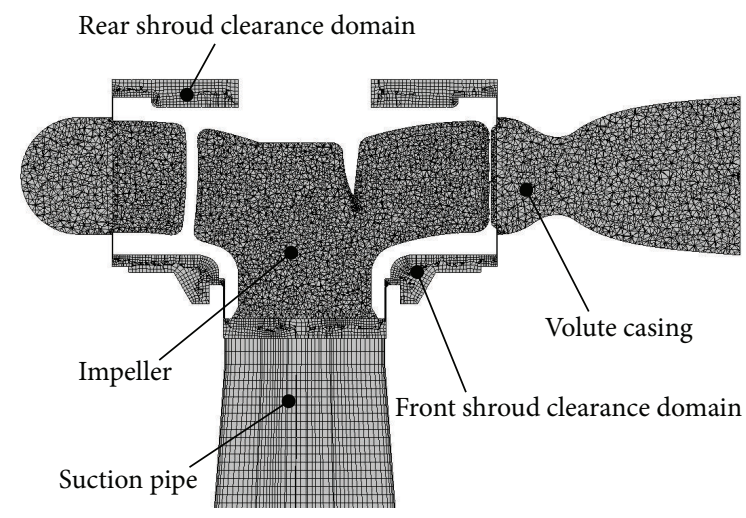

(b) Computational grids of pump part

Figure 7: Computational model. of elements in the gaps counted radially is five for the linerring gap and four for both the rear shroud part and front shroud part gaps. A nonstructured tetrahedral grid is used as the computational grid for the impeller and volute casing, whereas a nonstructured hexahedral grid is used for the others.

To study the dependence of the computational model on the grid used, we performed analyses for the $\beta_{b 2}=8$ case, where there were, respectively, 8,6 , and 6 elements in the radial direction in the liner-ring gap, rear shroud part gap, and front shroud part gap, and computational grids for the rear shroud part gap and front shroud part gap regions had 561,000 and 1,017,000 elements, respectively, with a total grid number of approximately 2,994,000 elements. The results showed that the errors in the flow rate, at the maximum efficiency point in the analysis results for the $\beta_{b 2}=8$ case, were $0.2 \%$ for the head, $0.3 \%$ for the shaft power, $0.7 \%$ for the root-mean-square value of the total radial thrust, and $4.1 \%$ for the time-averaged value of the total axial thrust. For an impeller with $\beta_{b 2}=8$, we performed analyses with volute casing computational grid numbers of $1,035,000$ and 693,000 elements, with a total grid number of approximately $2,904,000$ elements. The results showed that the errors in the flow rate, at the maximum efficiency point in the analysis results for the $\beta_{b 2}=8$ case, were $1.8 \%$ for the head, $1.6 \%$ for the shaft power, $0.6 \%$ for the root-mean-square value of the total radial thrust, and $3.7 \%$ for the time-averaged value of the total axial thrust. As mentioned above, we verified that the grid dependence for this computational model was comparatively small [15].

The boundary conditions for the suction pipe inlet were set as those on the inlet boundary and for the discharge pipe as those on the outlet boundary and were given as the mass flow rate on the inlet boundary, a static pressure (gauge pressure) on the outlet boundary of $0 \mathrm{~Pa}$, and the rotational speed in the impeller domain. The wall surface was assumed to be a nonslip condition, and the boundary between the rotating and static domains was conjugated using the transient rotor-stator technique [17]. The time step was set such that 360 steps were a single rotation of the impeller, and the calculations were continued until the fluctuations in the flow became practically constant.

\section{Experimental and Analysis Results and Considerations}

4.1. Comparison of Pump Performances. The pump performance for each different impeller based on both experiment and numerical analysis is shown in Figures 8(a)-8(c). Qualitatively, the experimental and calculated values for the cases $\beta_{b 2}=8$ and $\beta_{b 2}=16$ showed good agreement for the head coefficient $\psi$, shaft power coefficient $\lambda$, and pump efficiency $\eta$. The calculated values of $\psi$ are seen to increase in impellers for which the $\beta_{b 2}$ increases with increasing flow rate. With the flow rate at the point of maximum efficiency, $\varphi=0.030$, $\psi$ for $\beta_{b 2}=16$ and $\beta_{b 2}=24$ increased by $13.7 \%$ and $33.8 \%$, respectively, relative to $\beta_{b 2}=8$. This could be attributed to the increase in the circumferential component of the absolute 


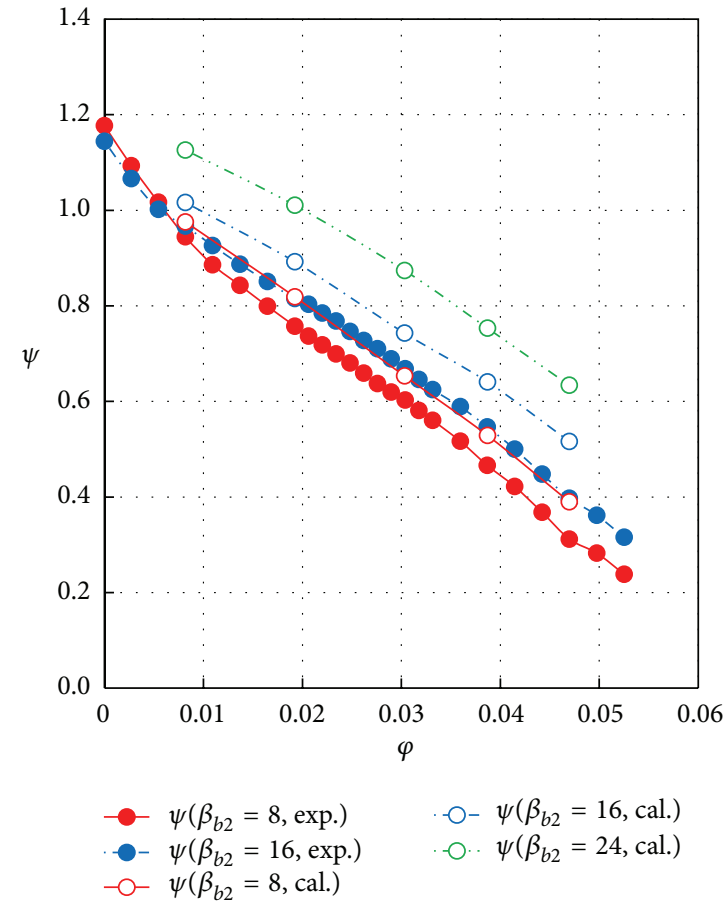

(a) Head coefficient

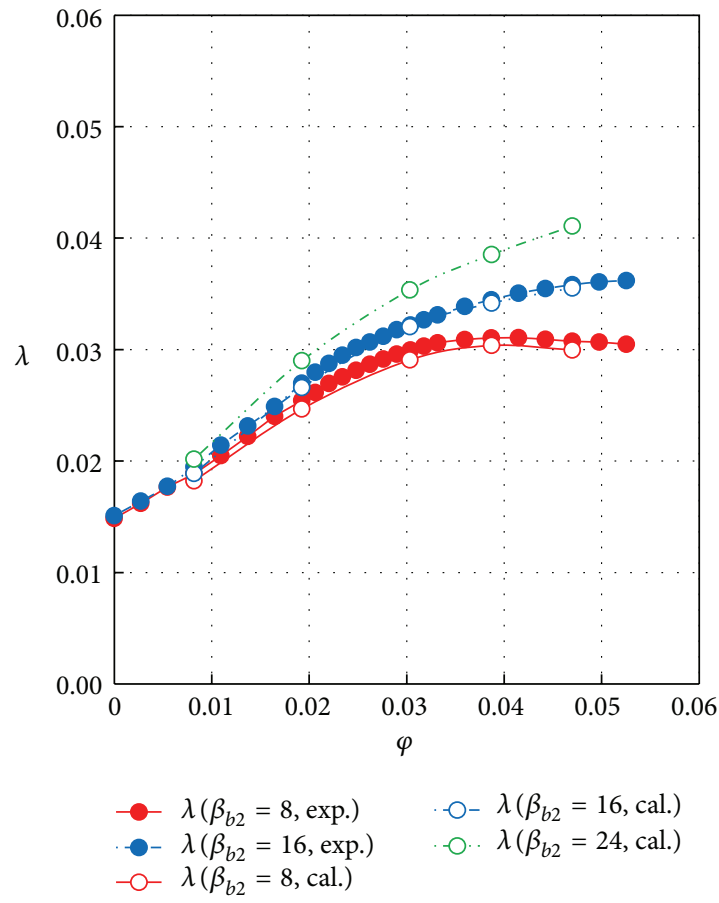

(b) Shaft power coefficient

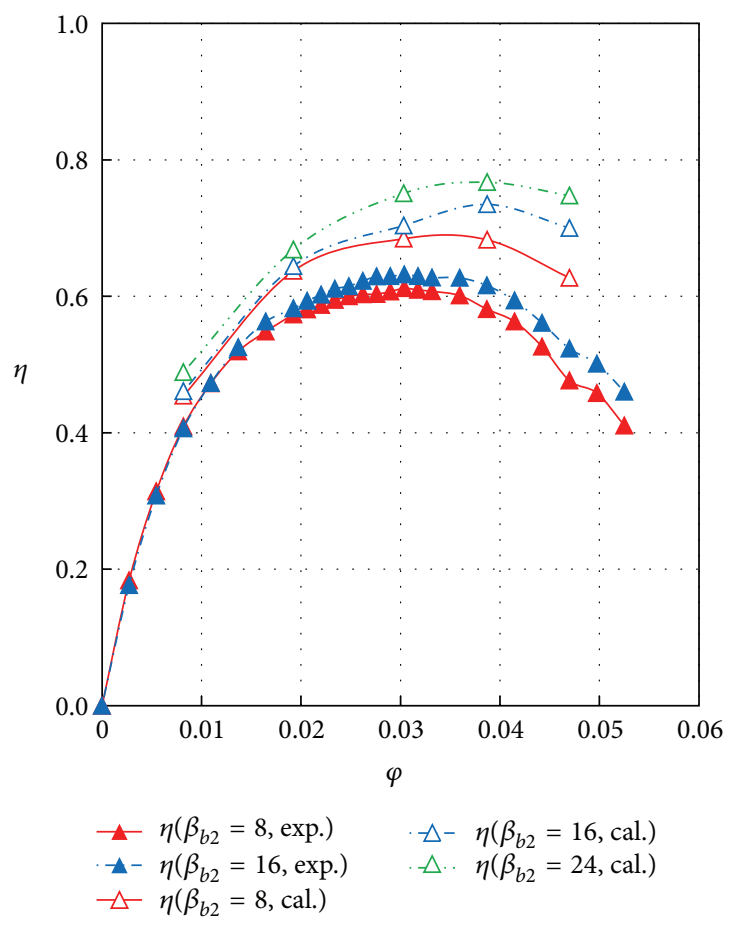

(c) Pump efficiency

FIGURE 8: Performance curves.

velocity of the blade outlet as the blade outlet angle increases, whereas, for the calculated values of $\eta$, the flow rate at the point of maximum efficiency with $\beta_{b 2}=8$ is $\varphi=0.030$ and that for $\beta_{b 2}=16$ and $\beta_{b 2}=24$ migrated to the larger side is $\varphi=0.039$. The $\eta$ for $\beta_{b 2}=16$ and $\beta_{b 2}=24$ at $\varphi=0.039$ was 0.735 and 0.767 , respectively, and we find that $\eta$ increases for impellers with larger $\beta_{b 2}$. The flow rate at the point of maximum efficiency is thought to be moving toward a larger flow rate because the theoretical pump head for a finite number of blades increases as the blade outlet angle increases, 


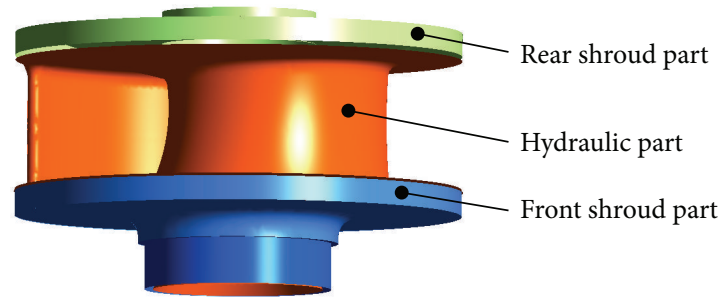

Figure 9: Impeller surfaces.

and the matching point with Worster's characteristic formula for the volute [18] then moves toward a larger flow rate.

4.2. Comparison of Radial Thrust. In this study, the impeller surface is divided into three regions, as shown in Figure 9. The blade surface is assumed to be the hydraulic part, the outer surface of the rear shroud part including its outer periphery as the rear shroud part, and the outer surface of the front shroud part including its outer periphery as the front shroud part. The total radial thrust $F_{r}$ acting on the impeller is expressed by the following formula $[14,15]$ :

$$
F_{r}=F_{r H}+F_{r R}+F_{r F} .
$$

Here, $F_{r H}$ is the radial thrust on the hydraulic part [N], $F_{r R}$ is the radial thrust on the rear shroud part [N], and $F_{r F}$ is the radial thrust on the front shroud part $[\mathrm{N}]$.

The radial thrust $F_{r}$ can be defined by the following formula as the vector sum of the time-averaged value (an average component) and a fluctuating component $[3,4,16]$ :

$$
F_{r}=\bar{F}_{r}+\Delta F_{r}
$$

Here, $\bar{F}_{r}$ is the time-averaged value and $\Delta F_{r}$ is the fluctuating component.

The time-averaged value $\bar{f}_{r}$ and the root-mean-square value of fluctuating component $\Delta f_{r}$ of the total radial thrust coefficient on the impeller from both experiment and numerical analysis are shown in Figure 10. The calculated value for radial thrust was found by integrating, over each of the impeller parts, the pressure acting on the wall surface and the shear stress on the wall surface. From Figure 10, the experimental and calculated values for $\bar{f}_{r}$ and the root-meansquare value of $\Delta f_{r}$ are seen to agree qualitatively. Although all the impellers show roughly the same values for the rootmean-square value of $\Delta f_{r}$ with a small flow rate of $\varphi=0.008$, at large flow rates, it increases for impellers with larger $\beta_{b 2}$. This is thought to be because, although it also depends on the load distribution on the blade, for large flow rates, there is a relative increase in the load on the blade for impellers with larger $\beta_{b 2}$. On the other hand, with $\bar{f}_{r}$, it increases for either a low flow rate or a high flow rate for whichever of the impellers, and there are comparatively small differences due to changes in $\beta_{b 2}$. This is believed to be due to the circumferential distribution of the time-averaged pressure coefficient $C_{P}$

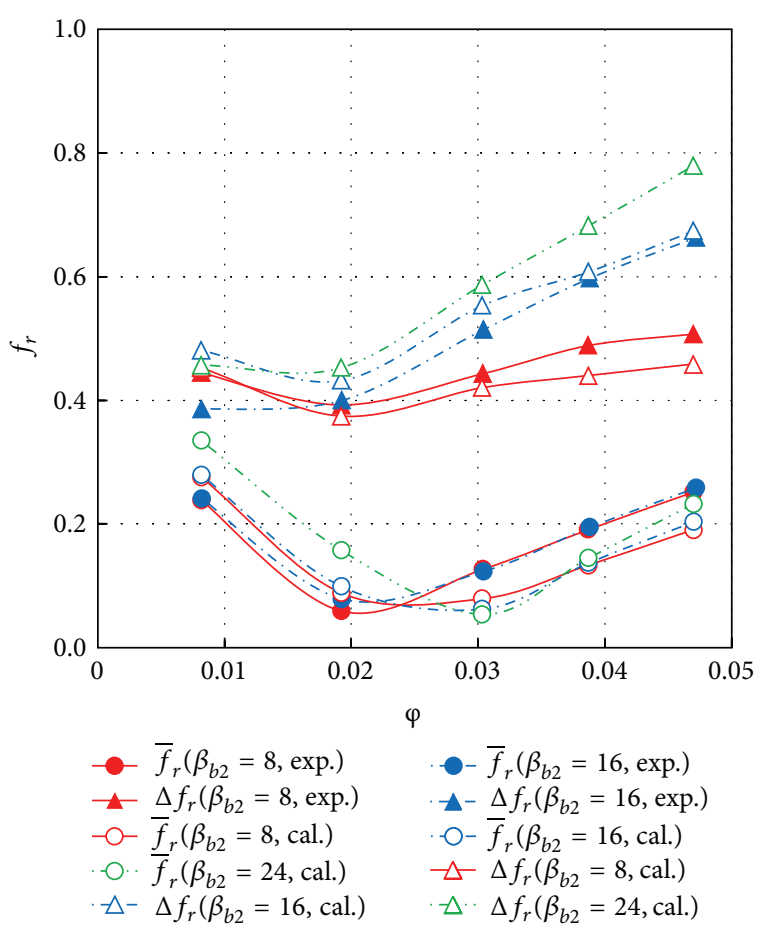

FIGURE 10: Time-averaged values of total radial thrust.

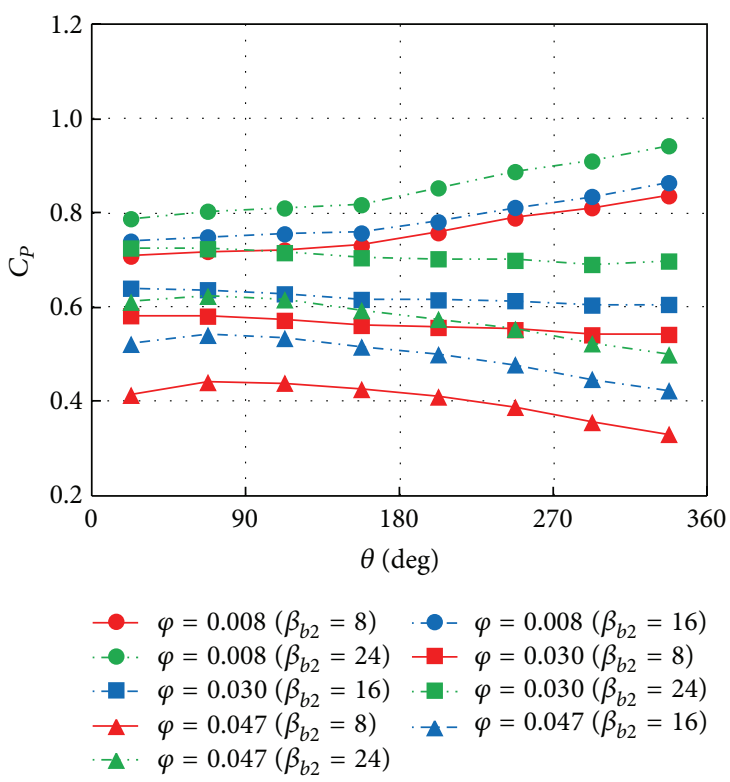

FIGURE 11: Time-averaged static pressure distributions (cal.).

at the monitor points in the impeller outlet shown in Figure 11, which are the results of numerical analysis; $C_{P}$ gets higher for impellers with larger $\beta_{b 2}$ for any of the flow rates, and that value increases uniformly. Thus, we have confirmed that there is good agreement between the experimental and calculated values of $C_{P}$ at the impeller outlet [15].

Subsequently, we investigate the behavior of the radial thrust acting on each part of the different impellers. The Lissajous figures for the radial thrust coefficient for the hydraulic 

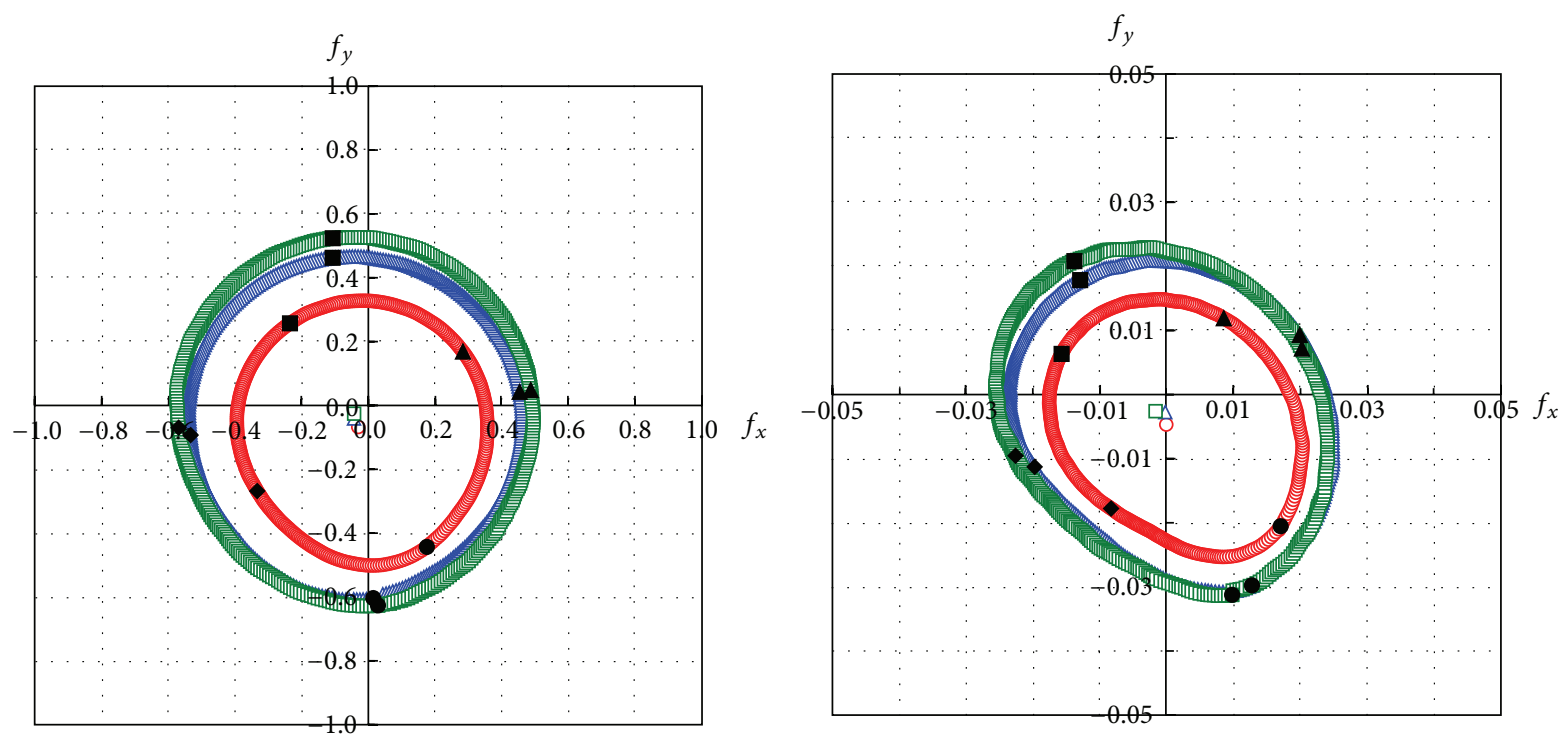
○ $\beta_{b 2}=8$
$\triangle \beta_{b 2}=16$
$\beta_{b 2}=24$
A $\theta_{0}=90^{\circ}$
- $\theta_{0}=180^{\circ}$
- $\theta_{0}=270^{\circ}$
- $\theta_{0}=0^{\circ}$

$\circ \beta_{b 2}=8$
$\triangle \beta_{b 2}=16$
$\square \beta_{b 2}=24$
- $\theta_{0}=0^{\circ}$

\ $\theta_{0}=90^{\circ}$

- $\theta_{0}=180^{\circ}$

- $\theta_{0}=270^{\circ}$

(a) Hydraulic part

(b) Rear shroud part

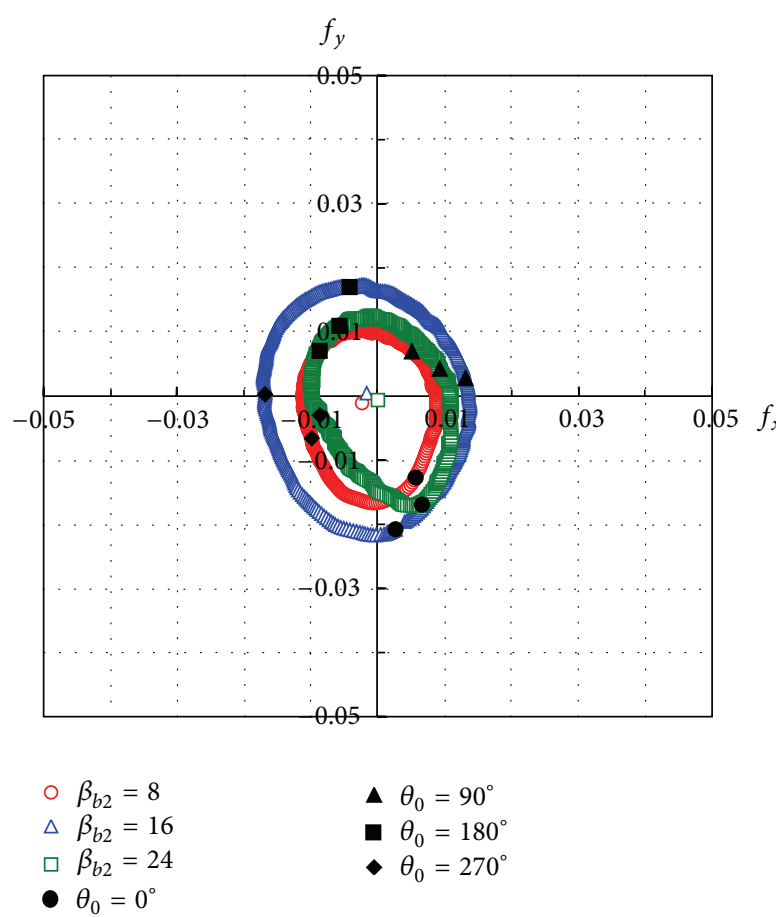

(c) Front shroud part

Figure 12: Lissajous figures of radial thrust which acts on each part $(\varphi=0.030$, cal.).

part, rear shroud part, and front shroud part of each impeller are shown in Figures 12(a)-12(c) for $\varphi=0.030$. For each radial thrust coefficient, the values at $\theta_{0}=0,90,180$, and 270 are shown, respectively, by $\boldsymbol{\bullet}, \mathbf{\Delta}, \mathbf{\square}$, and $\bullet$, and the time-averaged values are given using the same symbols as those for the radial thrust coefficient. These are represented similarly in
Figures 13(a) and 13(b). From Figures 12(a)-12(c), the timeaveraged value of the radial thrust acting on each part is located near the origin for any of the impellers. The fluctuating component of the radial thrust for both the hydraulic and rear shroud parts increases for impellers with larger $\beta_{b 2}$. However, in the case of radial thrust for the front 


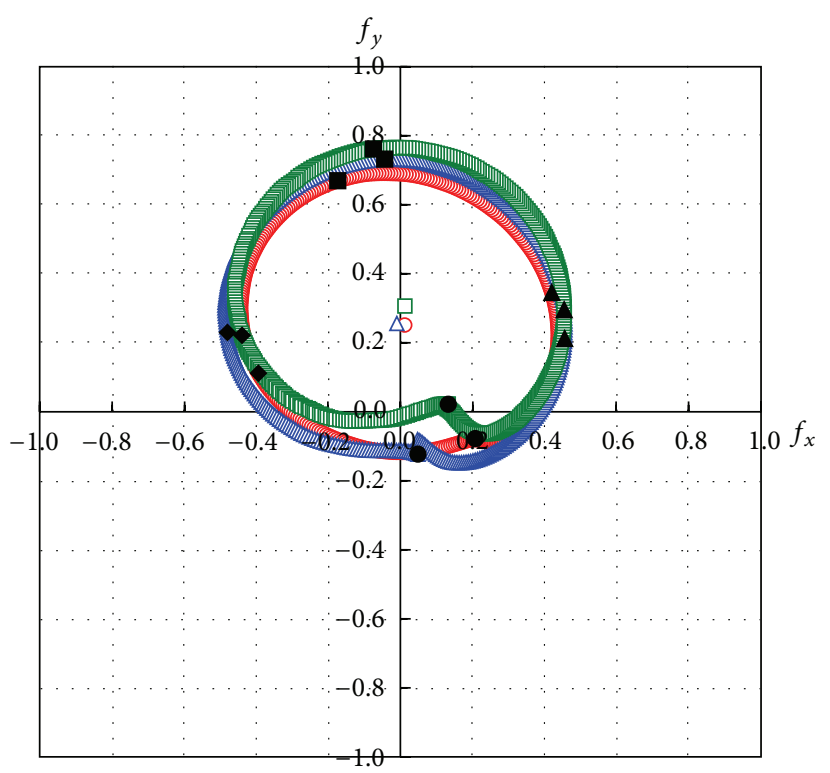
○ $\beta_{b 2}=8$
$\Delta \beta_{b 2}=16$
$\square \beta_{b 2}=24$
- $\theta_{0}=0^{\circ}$

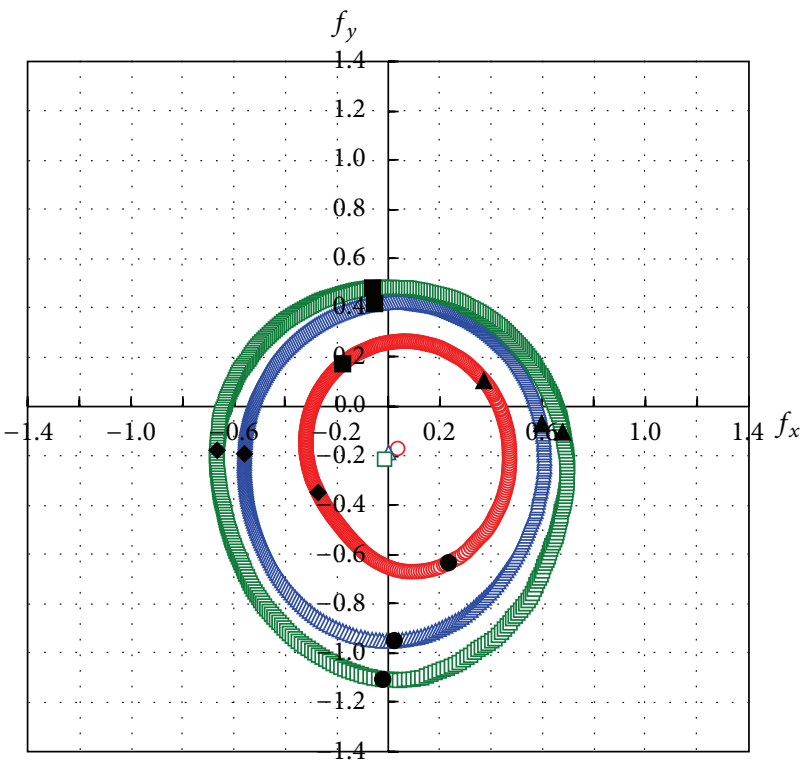

$\circ \beta_{b 2}=8$
$\triangle \beta_{b 2}=16$
$\square \beta_{b 2}=24$
- $\theta_{0}=0^{\circ}$

(a) $\varphi=0.008$

(b) $\varphi=0.047$

FIGURE 13: Lissajous figures of hydraulic part radial thrust (cal.).

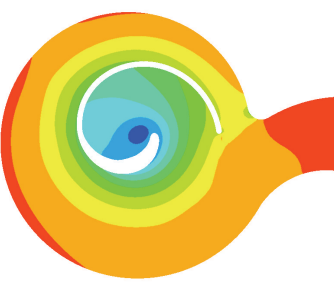

(a) $\theta_{0}=0^{\circ}$

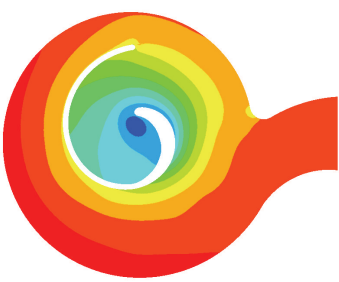

(b) $\theta_{0}=90^{\circ}$

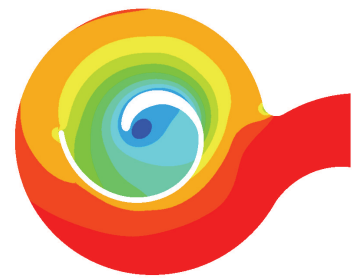

(c) $\theta_{0}=180^{\circ}$

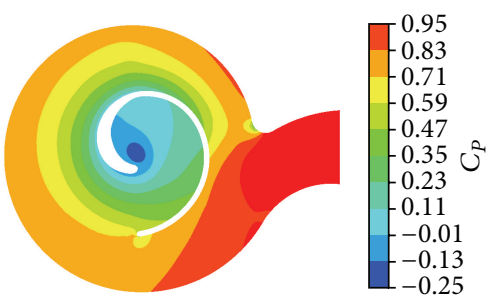

(d) $\theta_{0}=270^{\circ}$

FIGURE 14: Static pressure distributions at blade width central $\left(\varphi=0.008, \beta_{b 2}=8\right)$.

shroud part, it is smaller for the impeller with $\beta_{b 2}=24$ than for the one with $\beta_{b 2}=16$. Because a leakage flow exists on the side of the front shroud part, the effect of an increase in the leakage flow rate for the impeller with $\beta_{b 2}=24$ (discussed later) can reasonably be considered as the reason for this finding. Moreover, we find that the radial thrust for the rear shroud and front shroud parts is small in relation to the radial thrust for the hydraulic part for all the impellers. It therefore follows that the radial thrust for the hydraulic part dominates the total radial thrust.

Thus, concentrating on the radial thrust coefficient for the hydraulic part, its Lissajous figure is shown in Figures 13(a) and 13(b) for the low flow rate $\varphi=0.008$ and high flow rate $\varphi=0.047$. With the low flow rate $\varphi=0.008$, the radial thrust for the hydraulic part is large in the vicinity of $\theta_{0}=180^{\circ}$, and it is largest for the impeller with $\beta_{b 2}=24$. On the contrary, the radial thrust for the hydraulic part is small in the vicinity of $\theta_{0}=0^{\circ}$, and it is smallest for the impeller with $\beta_{b 2}=24$.

On the other hand, with the high flow rate $\varphi=0.047$, the radial thrust for the hydraulic part is large in the vicinity of $\theta_{0}=0^{\circ}$, and it is largest for the impeller with $\beta_{b 2}=24$. Conversely, the radial thrust for the hydraulic part is small in the vicinity of $\theta_{0}=180^{\circ}$ and is smallest for the impeller with $\beta_{b 2}=8$. As shown with the numerical analyses in Figures 14(a)-14(d), 15(a)-15(d), 16(a)-16(d), and 17(a)-17(d), from the static pressure distribution on the impellers with $\beta_{b 2}=$ 8 and $\beta_{b 2}=24$, at both $\varphi=0.008$ and $\varphi=0.047$, the following observations can be made. The cross-section is in the center of the blade width. At the low flow rate $\varphi=0.008$, the timeaveraged $C_{P}$ increases as the end of the volute winding is approached. Moreover, if $\theta_{0}=180^{\circ}$, because $C_{P}$ for a pressure surface with $180^{\circ}<\theta<360^{\circ}$ increases more, the radial thrust 


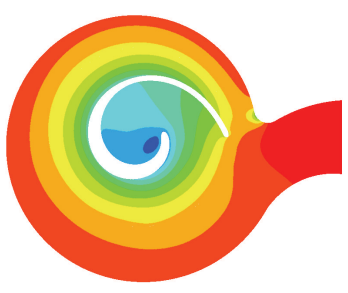

(a) $\theta_{0}=0^{\circ}$

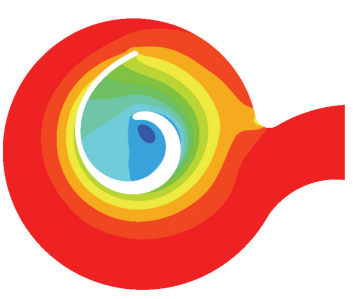

(b) $\theta_{0}=90^{\circ}$

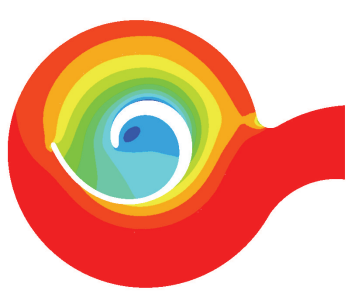

(c) $\theta_{0}=180^{\circ}$

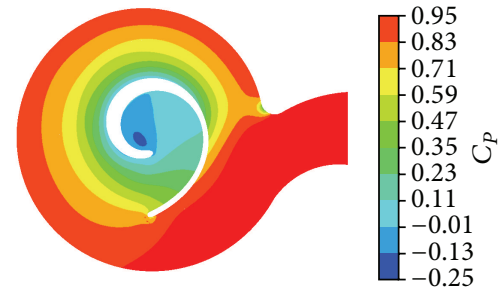

(d) $\theta_{0}=270^{\circ}$

FIGURE 15: Static pressure distributions at blade width central $\left(\varphi=0.008, \beta_{b 2}=24\right)$.

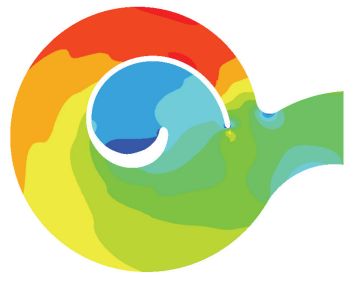

(a) $\theta_{0}=0^{\circ}$

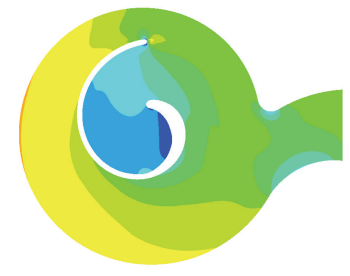

(b) $\theta_{0}=90^{\circ}$

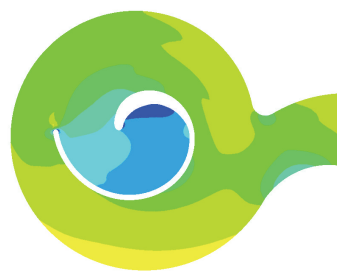

(c) $\theta_{0}=180^{\circ}$

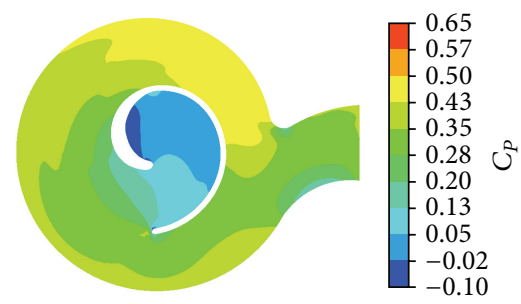

(d) $\theta_{0}=270^{\circ}$

FIgURE 16: Static pressure distributions at blade width central $\left(\varphi=0.047, \beta_{b 2}=8\right)$.

for the hydraulic part acts in the $+y$-axis direction. For a large blade outlet angle of $\beta_{b 2}=24$, both the $C_{P}$ for the pressure surface and time-averaged $C_{P}$ at the end of the volute winding are the largest, and the radial thrust for the hydraulic part in that case is the largest. However, if $\theta_{0}=0^{\circ}$, the $C_{P}$ for a pressure surface with $0^{\circ}<\theta<180^{\circ}$ is increased, and the $C_{P}$ for $\beta_{b 2}=24$ is the largest. However, owing to the effect of the time-averaged $C_{P}$, which increases as the end of the volute winding is approached, the time-averaged value of the radial thrust for the hydraulic part acts largely in the $+y$-axis direction. Therefore, the radial thrust for the hydraulic part can be considered to act in the $-y$-axis direction in terms of its time-averaged value. For $\beta_{b 2}=24$, the time-averaged $C_{P}$ is the largest, and the radial thrust for the hydraulic part is the smallest. On the other hand, with a flow rate $\varphi=0.047$, the time-averaged $C_{P}$ increases as the beginning of the volute winding is approached. Moreover, if $\theta_{0}=0^{\circ}$, because the $C_{P}$ for a pressure surface with $0^{\circ}<\theta<180^{\circ}$ increases more, the radial thrust for the hydraulic part acts in the $-Y$ direction. For $\beta_{b 2}=24$, both the $C_{P}$ for the pressure surface and timeaveraged $C_{P}$ at the beginning of the volute winding are the largest, and the radial thrust for the hydraulic part is the largest. On the contrary, if $\theta_{0}=180^{\circ}, C_{P}$ for a pressure surface with $180^{\circ}<\theta<360^{\circ}$ is increased. However, due to the effect of the time-averaged $C_{P}$, which decreases as the end of the volute winding is approached, the time-averaged value of the radial thrust for the hydraulic part acts largely in the $-y$-axis direction. Therefore, the radial thrust for the hydraulic part can be considered to act in the $+y$-axis direction in terms of its time-averaged value. For $\beta_{b 2}=8$, both the $C_{P}$ for the pressure surface and time-averaged $C_{P}$ at the end of the volute winding are the smallest, and the radial thrust for the hydraulic part can then be considered to have its smallest value.
4.3. Comparison of Axial Thrust. Similar to the radial thrust in the previous section, the total axial thrust $F_{a}$ acting on the impeller is expressed by the following formula $[14,15]$ :

$$
F_{a}=F_{a H}+F_{a R}+F_{a F} .
$$

Here, $F_{a H}$ is the axial thrust for the hydraulic part [N], $F_{a R}$ is the axial thrust for the rear shroud part $[\mathrm{N}]$, and $F_{a F}$ is the axial thrust for the front shroud part $[\mathrm{N}]$.

The time-averaged values of the axial thrust coefficient for the hydraulic part, rear shroud part, and front shroud part are shown for each of the impellers in Figures 18(a) and 18(b). The calculated value for the axial thrust was found in a similar manner to that for the radial thrust, where the pressure acting on the wall surfaces and the shear stress on the wall surfaces is integrated overall into each part of the impeller. Comparing the absolute values of the axial thrust coefficient for each part and for all the impellers, the axial thrust coefficient $f_{a H}$ for the hydraulic part is the smallest. The axial thrust coefficients for the rear shroud part $f_{a R}$ and front shroud part $f_{a F}$ are dominant, unlike the cases for the radial thrust. $f_{a R}$ and $f_{a F}$ are in opposing directions relative to each other, and their absolute values increase for smaller flow rates. Moreover, $f_{a R}$ is larger than $f_{a F}$, from which it follows that the total axial thrust coefficient $f_{a}$ acts in the $-z$ axis direction and its absolute value increases for smaller flow rates.

Comparing the individual impellers, the absolute value of the total axial thrust coefficient $f_{a}$ is the largest for $\beta_{b 2}=$ 24. Little difference exists between $\beta_{b 2}=8$ and $\beta_{b 2}=16$; however, for small flow rates, the difference is slightly larger for $\beta_{b 2}=8$. The larger the $\beta_{b 2}$ for the impeller is, the more the absolute values of $f_{a R}$ and $f_{a F}$ increase at high flow rates. However, when the blade outlet angle $\beta_{b 2}$ is varied from $8^{\circ}$ 


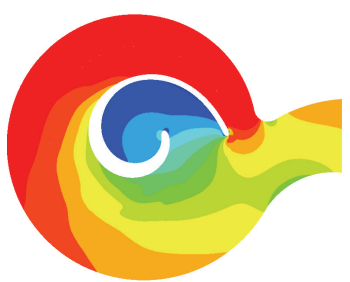

(a) $\theta_{0}=0^{\circ}$

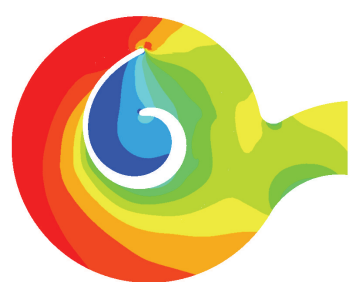

(b) $\theta_{0}=90^{\circ}$

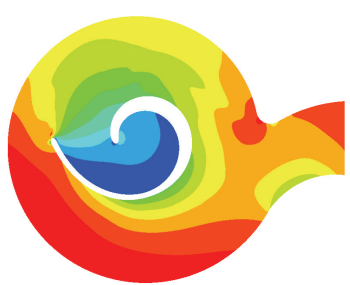

(c) $\theta_{0}=180^{\circ}$

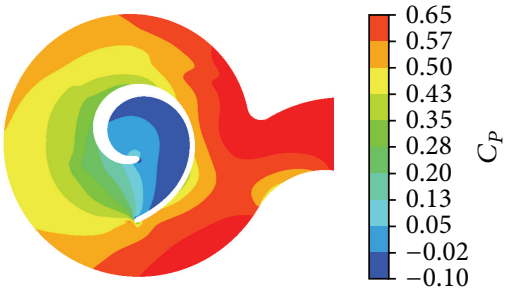

(d) $\theta_{0}=270^{\circ}$

FIGURE 17: Static pressure distributions at blade width central $\left(\varphi=0.047, \beta_{b 2}=24\right)$.

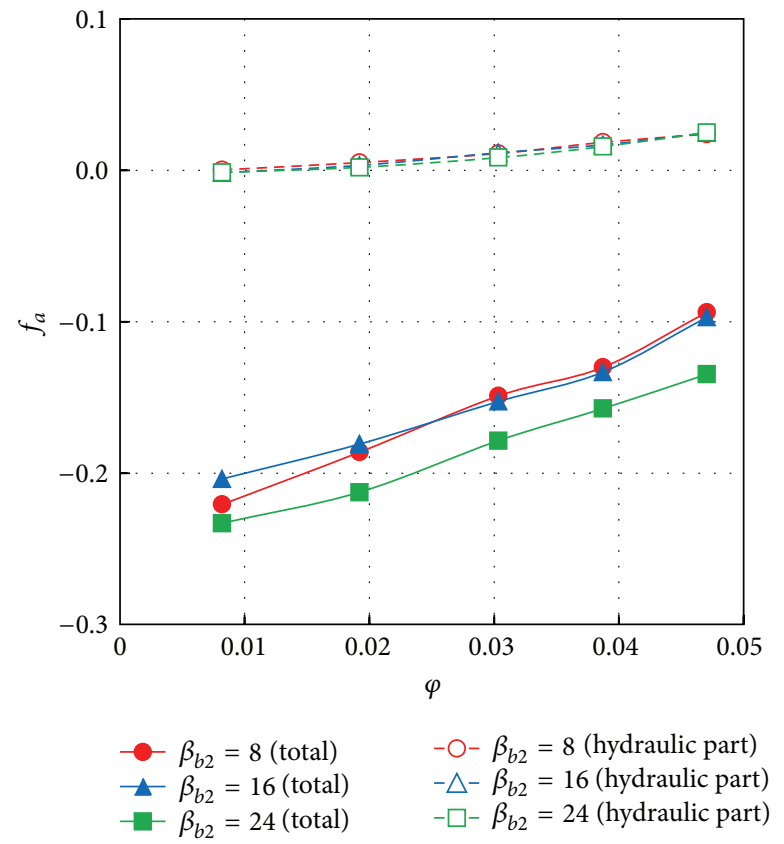

(a) Total and hydraulic part

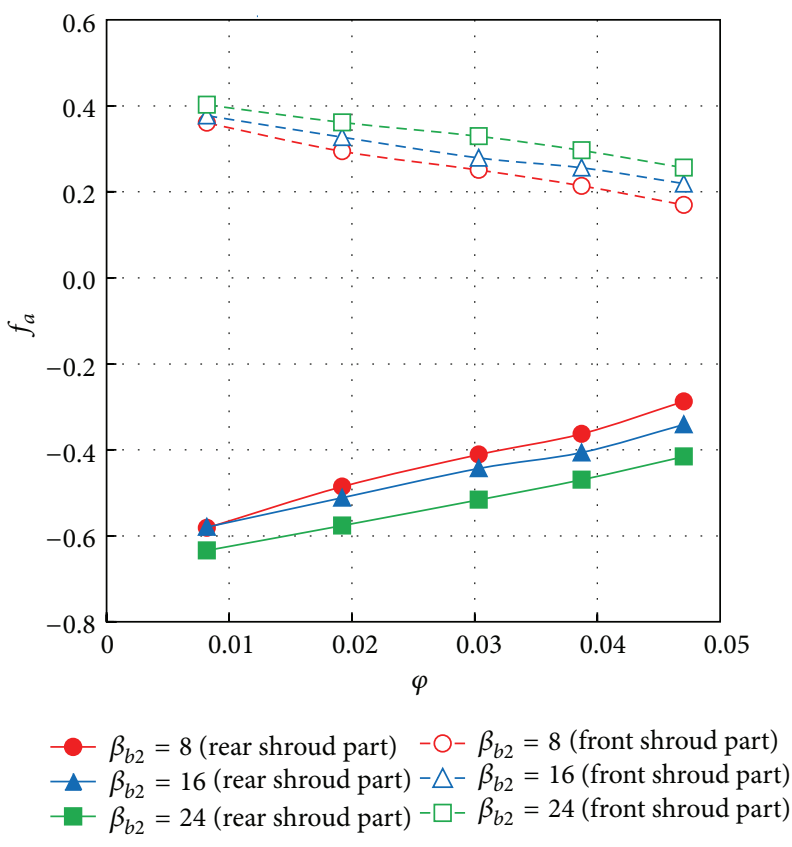

(b) Rear and front shroud parts

FIgURE 18: Time-averaged values of axial thrust which acts on each part (cal.).

to $16^{\circ}$, the increase in the absolute value of $f_{a R}$ is relatively small compared with the increase in the absolute value of $f_{a F}$, and for $\varphi=0.008$ in particular, the absolute values of $f_{a R}$ for $\beta_{b 2}=8$ and $\beta_{b 2}=16$ approximately agree.

Concentrating on the total axial thrust and the axial thrust on the rear and front shroud parts for $\varphi=0.008$ and $\varphi=0.047$, the fluctuation of $f_{a}, f_{a R}$, and $f_{a F}$ during a single rotation of the impeller is shown in Figures 19(a)-19(c). From Figure 19(a), the axial thrust coefficient $f_{a}$ for all the impellers shows a similar behavior and fluctuates greatly during a single rotation of the impeller. The absolute value of $f_{a}$ is largest in the vicinity of $\theta_{0}=90^{\circ}-180^{\circ}$ for a low flow rate $\varphi=0.008$, but conversely, for a high flow rate $\varphi=0.047$, the largest value is at $\theta=0^{\circ}\left(360^{\circ}\right)$. From Figures 19(b) and 19(c), the absolute values of $f_{a R}$ and $f_{a F}$ also behave in a manner similar to the absolute value of $f_{a}$. Therefore, for all the impellers, the total axial thrust is partially offset by the axial thrust of the front shroud part, but we see a behavior roughly similar to the axial thrust for the rear shroud part.
For impellers with $\beta_{b 2}=8$ and $\beta_{b 2}=24$, we investigated the axial thrust for the rear and front shroud parts in relation to the pressure field. For a low flow rate $\varphi=0.008$, the static pressure distribution in the clearance domain for the rear and front shrouds for the $\beta_{b 2}=8$ case is shown in Figures 20(a)-20(d) and 21(a)-21(d), respectively, whereas the same pressure distributions for the case $\beta_{b 2}=24$ are shown in Figures 22(a)-22(d) and 23(a)-23(d), respectively. Furthermore, the same pressure distributions are shown for a high flow rate $\varphi=0.047$ in Figures 24(a)-24(d) and 25(a)25(d) for $\beta_{b 2}=8$ and in Figures 26(a)-26(d) and 27(a) $-27(\mathrm{~d})$ for $\beta_{b 2}=24$. Here, the static pressure distribution in the clearance domain for the front and rear shrouds is for the cross-sections $\mathrm{C}-\mathrm{C}$ and $\mathrm{D}-\mathrm{D}$, respectively, of Figure 3. For any of the impellers, the $C_{P}$ in the clearance domain of either the front or rear shroud fluctuates greatly during rotation of the impeller in the same way as the static pressure distribution in the interior of the pump, as shown in Figures 14-17. For a low flow rate $\varphi=0.008$, the $C_{P}$ for the clearance domain 


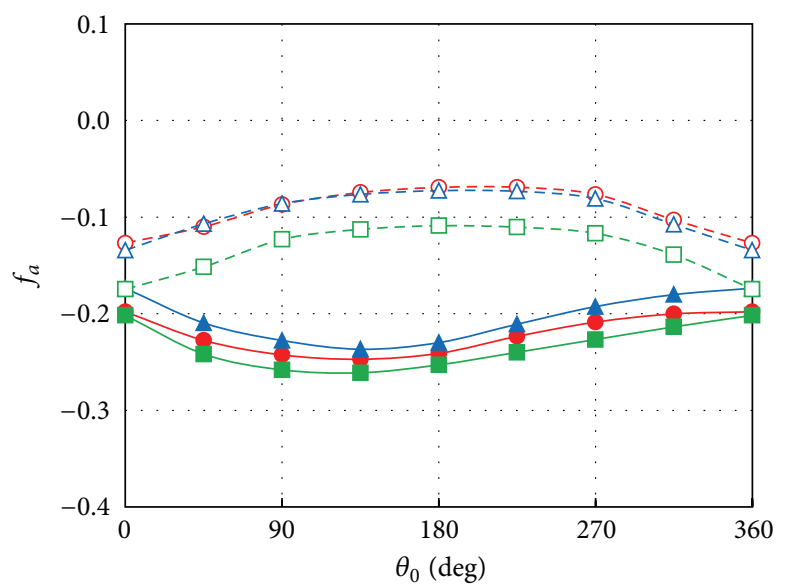

$\begin{array}{ll}\longrightarrow \beta_{b 2}=8(\varphi=0.008) & -\beta_{b 2}=16(\varphi=0.008) \\ -\beta_{b 2}=24(\varphi=0.008) & -\bigcirc-\beta_{b 2}=8(\varphi=0.047) \\ -\Delta-\beta_{b 2}=16(\varphi=0.047) & -\square-\beta_{b 2}=24(\varphi=0.047)\end{array}$

(a) Total

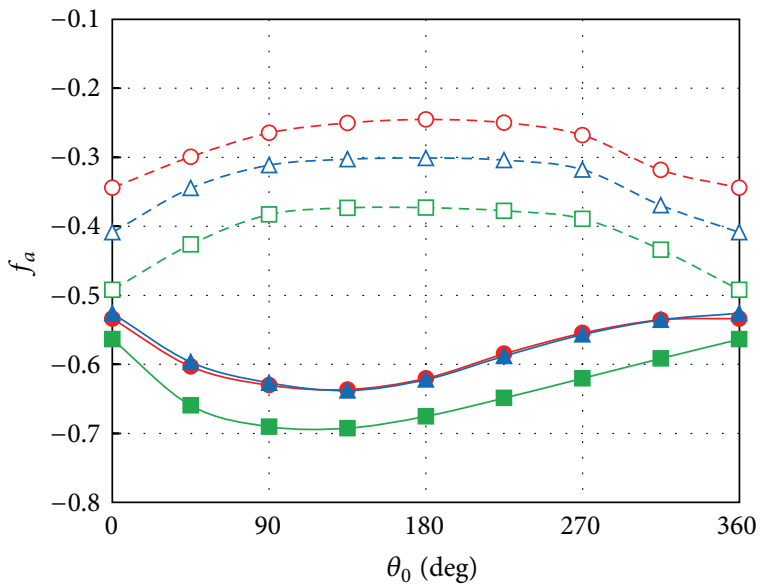

$\longrightarrow \beta_{b 2}=8(\varphi=0.008) \longrightarrow \beta_{b 2}=16(\varphi=0.008)$

$-\beta_{b 2}=24(\varphi=0.008)-0-\beta_{b 2}=8(\varphi=0.047)$

$-\triangle-\beta_{b 2}=16(\varphi=0.047) \quad-\square-\beta_{b 2}=24(\varphi=0.047)$

(b) Rear shroud part

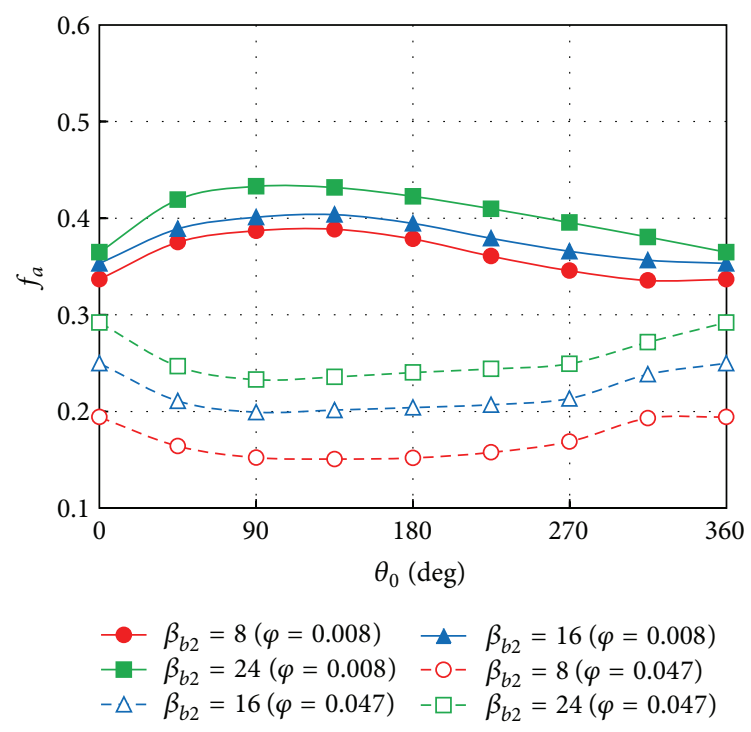

(c) Front shroud part

FIGURE 19: Axial thrust fluctuation which acts on each part (cal.).

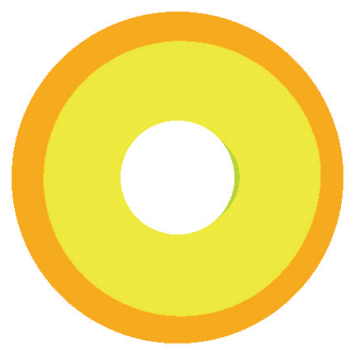

(a) $\theta_{0}=0^{\circ}$

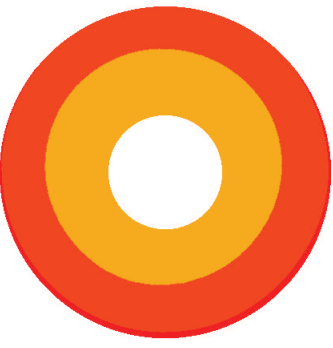

(b) $\theta_{0}=90^{\circ}$

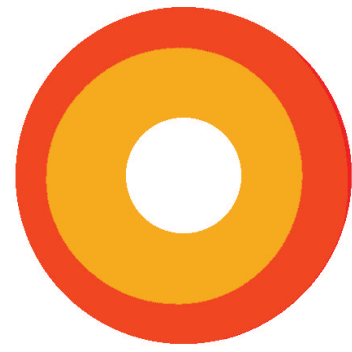

(c) $\theta_{0}=180^{\circ}$

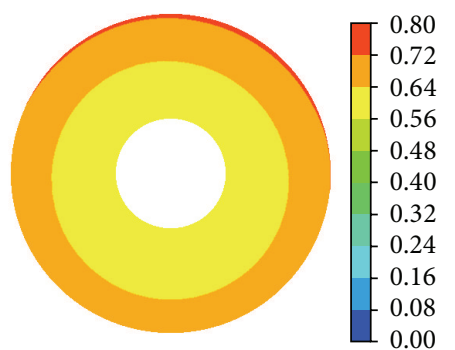

(d) $\theta_{0}=270^{\circ}$

FIGURE 20: Static pressure distributions at rear shroud $\left(\varphi=0.008, \beta_{b 2}=8\right)$. 


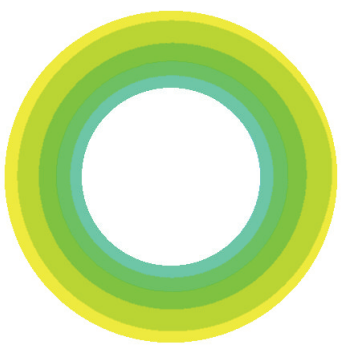

(a) $\theta_{0}=0^{\circ}$

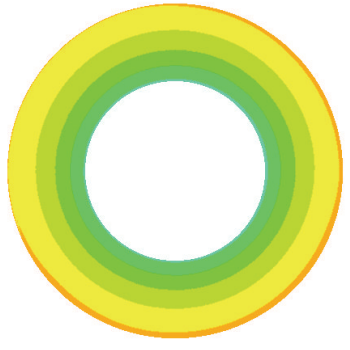

(b) $\theta_{0}=90^{\circ}$

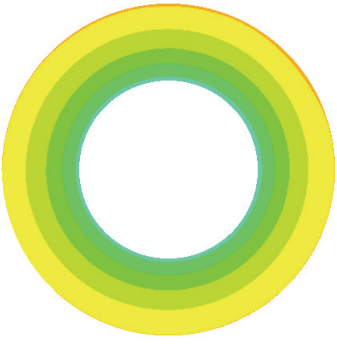

(c) $\theta_{0}=180^{\circ}$

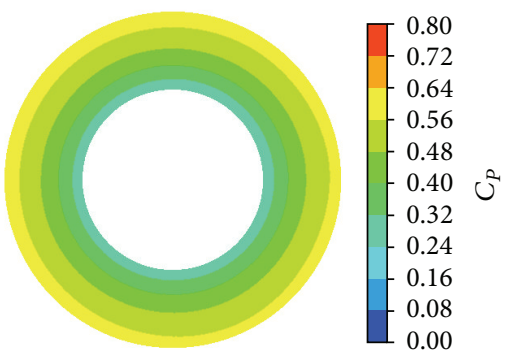

(d) $\theta_{0}=270^{\circ}$

FIGURE 21: Static pressure distributions at front shroud $\left(\varphi=0.008, \beta_{b 2}=8\right)$.

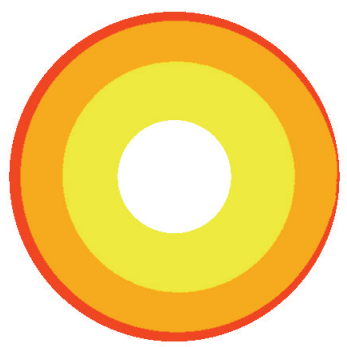

(a) $\theta_{0}=0^{\circ}$

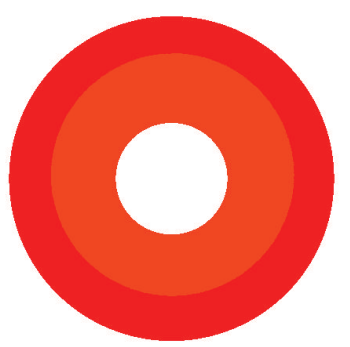

(b) $\theta_{0}=90^{\circ}$

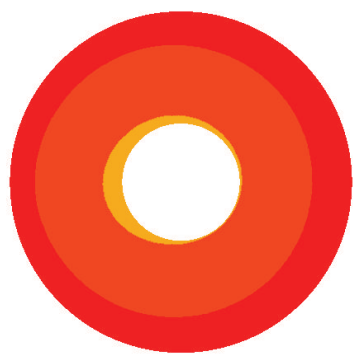

(c) $\theta_{0}=180^{\circ}$

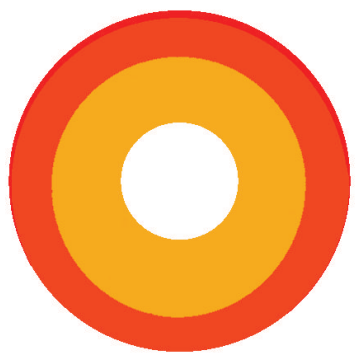

(d) $\theta_{0}=270^{\circ}$

FIGURE 22: Static pressure distributions at rear shroud $\left(\varphi=0.008, \beta_{b 2}=24\right)$.

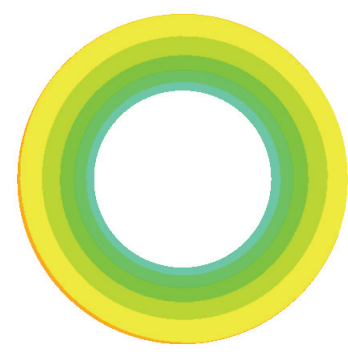

(a) $\theta_{0}=0^{\circ}$

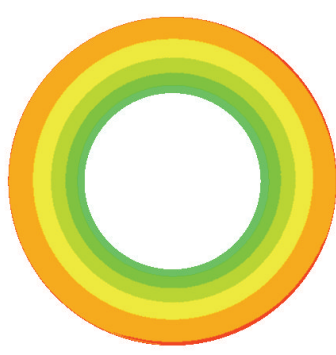

(b) $\theta_{0}=90^{\circ}$

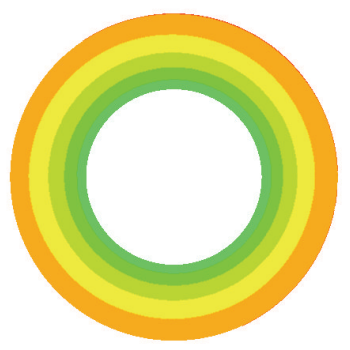

(c) $\theta_{0}=180^{\circ}$

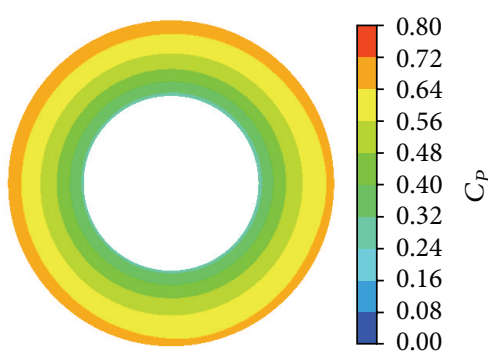

(d) $\theta_{0}=270^{\circ}$

FIGURE 23: Static pressure distributions at front shroud $\left(\varphi=0.008, \beta_{b 2}=24\right)$.

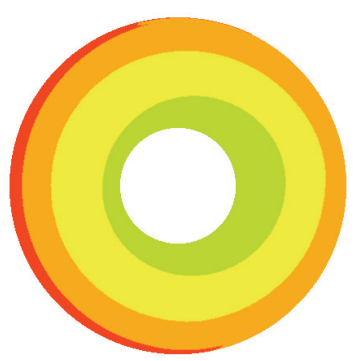

(a) $\theta_{0}=0^{\circ}$

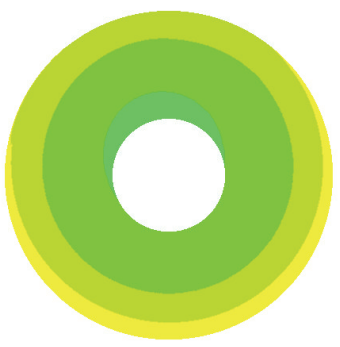

(b) $\theta_{0}=90^{\circ}$

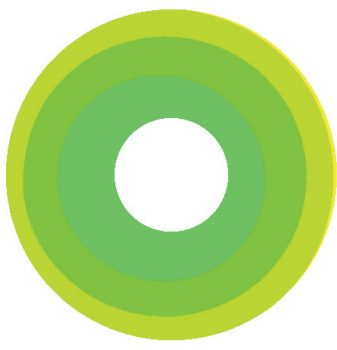

(c) $\theta_{0}=180^{\circ}$

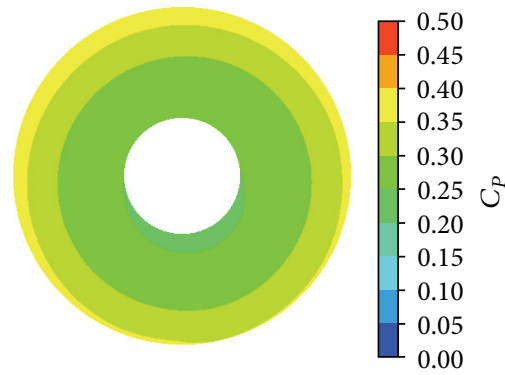

(d) $\theta_{0}=270^{\circ}$

FIGURE 24: Static pressure distributions at rear shroud $\left(\varphi=0.047, \beta_{b 2}=8\right)$. 


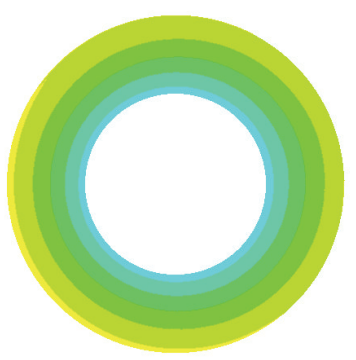

(a) $\theta_{0}=0^{\circ}$

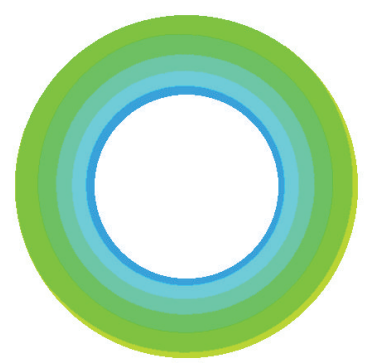

(b) $\theta_{0}=90^{\circ}$

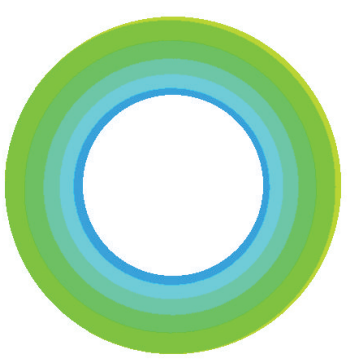

(c) $\theta_{0}=180^{\circ}$

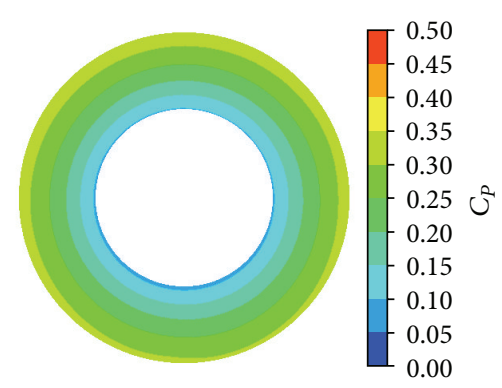

(d) $\theta_{0}=270^{\circ}$

FIGURE 25: Static pressure distributions at front shroud $\left(\varphi=0.047, \beta_{b 2}=8\right)$.

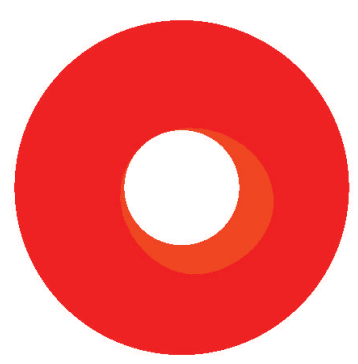

(a) $\theta_{0}=0^{\circ}$

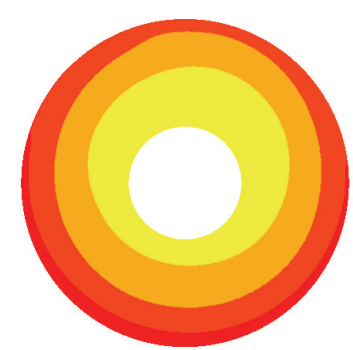

(b) $\theta_{0}=90^{\circ}$

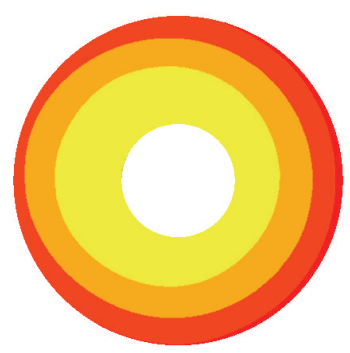

(c) $\theta_{0}=180^{\circ}$

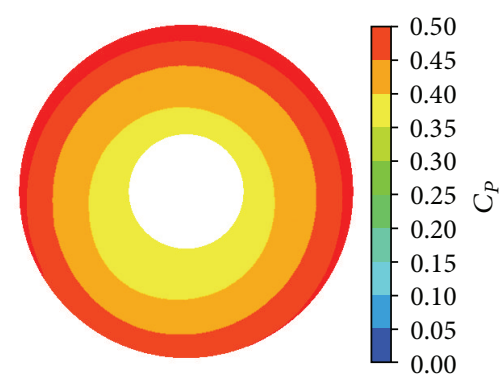

(d) $\theta_{0}=270^{\circ}$

FIGURE 26: Static pressure distributions at rear shroud $\left(\varphi=0.047, \beta_{b 2}=24\right)$.

of the front shroud takes a high value for all the impellers in the region $\theta_{0}=90^{\circ}-180^{\circ}$. Owing to the effect of leakage flow, the $C_{P}$ for the clearance domain of the front shroud drops overall below that for the clearance domain of the rear shroud but similarly takes a high value in the region $\theta_{0}=90^{\circ}-$ $180^{\circ}$, which corresponds to the behavior of the axial thrust for the rear and front shroud parts, shown, respectively, in Figures 19(b) and 19(c). At this point, if we examine the static pressure distribution in the interior of the pump, as shown in Figures 14 and 15, the static pressure around the impeller is greater overall in the region $\theta_{0}=90^{\circ}-180^{\circ}$ than in the region $\theta_{0}=180^{\circ}-270^{\circ}$. That is to say, we can reason that when the static pressure around the impeller increases overall, the static pressure in the clearance domain for the front and rear shrouds increases in accordance with the increase in the leakage flow rate. This is evident from the fact that if we consider the fluctuation in the leakage flow rate coefficient $C_{q}$ from the liner ring as shown in Figure 28(a) with $\varphi=0.008$, $C_{q}$ for any of the impellers attains its maximum value in the vicinity of $\theta_{0}=90^{\circ}-180^{\circ}$, which is larger; the larger value is the $\beta_{b 2}$ for the impeller.

On the other hand, for a large flow rate $\varphi=0.047$, the $C_{P}$ for the clearance domain of the front and rear shrouds takes a high value at $\theta_{0}=0^{\circ}\left(360^{\circ}\right)$, which corresponds to the behavior of the axial thrust for the rear and front shroud parts, as shown in Figures 19(b) and 19(c). At this point, looking at the static pressure distribution in the interior of the pump as shown in Figures 16 and 17, the static pressure around the impeller at $\theta_{0}=0^{\circ}$ is higher overall than in the region $\theta_{0}=$ $180^{\circ}-270^{\circ}$. It therefore follows that, as shown in Figure 28(b), for $\varphi=0.047, C_{q}$ attains its maximum value in the vicinity of $\theta_{0}=0^{\circ}$, which is larger; the larger value is $\beta_{b 2}$ for the impeller.

From the above considerations, because the timeaveraged $C_{P}$ at the end of the volute winding for low flow rates is large, in the region $\theta_{0}=90^{\circ}-180^{\circ}$, and because the time-averaged $C_{P}$ at the beginning of the volute winding for large flow rates is large, at $\theta_{0}=0^{\circ}$, the high $C_{P}$ of the pressure side propagates in the circumferential direction and the $C_{P}$ around the impeller increases. We can assume that accompanying the increase in this $C_{P}$, the leakage flow rate also increases, and owing to the high pressure acting on the outer surface of the rear and front shrouds, the axial thrust for the rear and front shroud parts therefore increases. Because the larger the blade outlet angle for the impeller, the higher the $C_{P}$ of the pressure side and time-averaged $C_{P}$ at either the beginning or end of the volute winding. We can argue that this tendency is very pronounced.

\section{Conclusions}

From the results of investigating the effect of the blade outlet angle on the fluctuating hydrodynamic forces in a closed-type centrifugal pump with a single blade, using both experiment and numerical analysis, we have found the following.

(1) At low flow rates, all the impellers give a root-meansquare value for the fluctuating component of the total radial thrust that is roughly the same, but for high flow rates, it is larger for impellers with larger blade outlet angles. On the other hand, although 


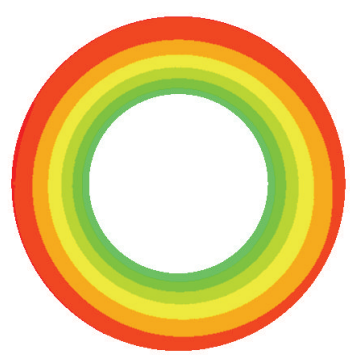

(a) $\theta_{0}=0^{\circ}$

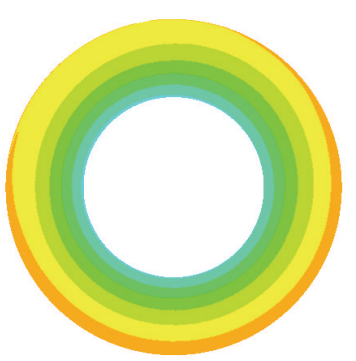

(b) $\theta_{0}=90^{\circ}$

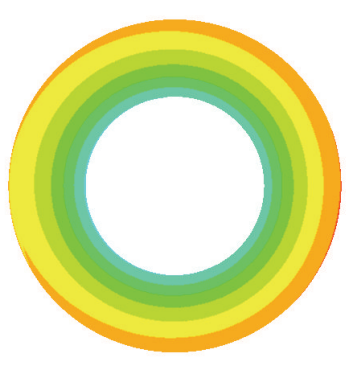

(c) $\theta_{0}=180^{\circ}$

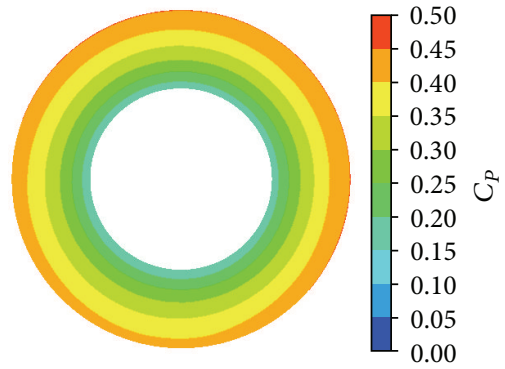

(d) $\theta_{0}=270^{\circ}$

FIGURE 27: Static pressure distributions at front shroud $\left(\varphi=0.047, \beta_{b 2}=24\right)$.

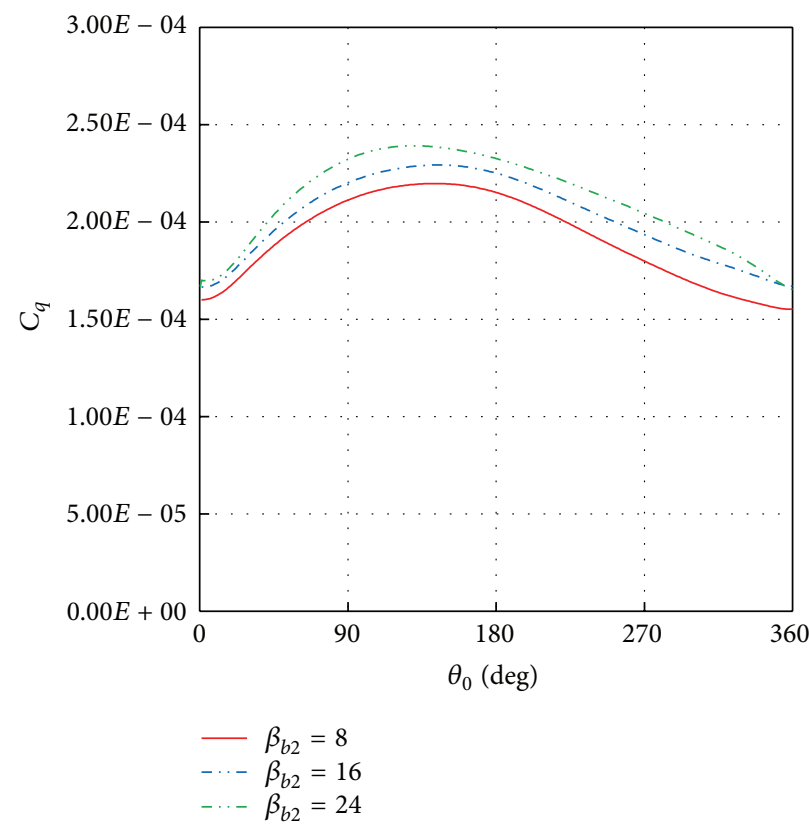

(a) $\varphi=0.008$

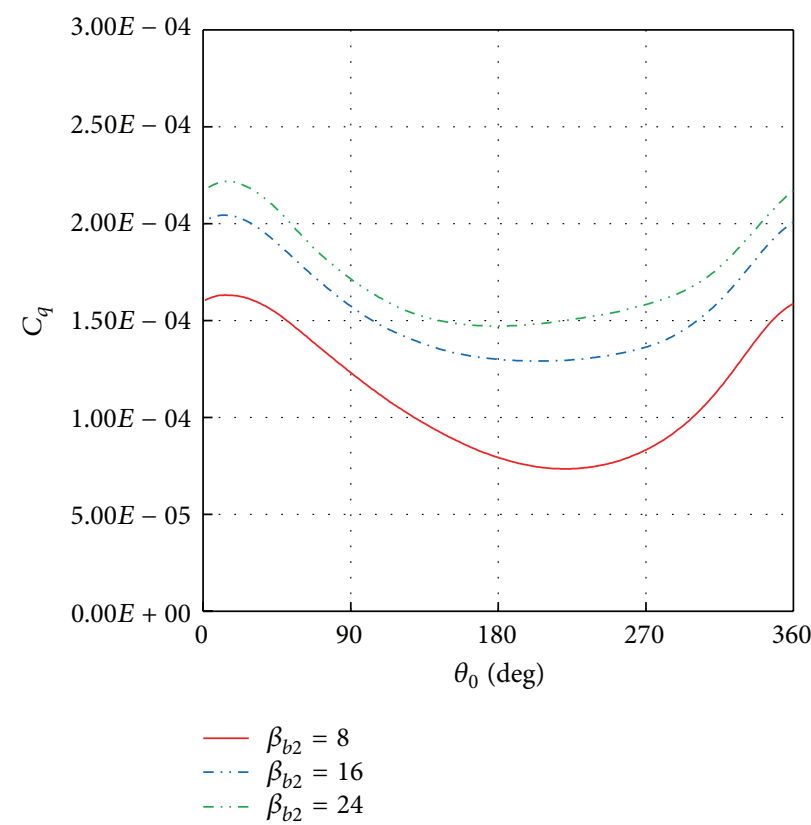

(b) $\varphi=0.047$

FIgURE 28: Leakage flow rate fluctuation (cal.).

the time-averaged value of the total radial thrust also increases with the flow rate for all the impellers, for either low or high flow rates, the difference due to variations in the blade outlet angle is comparatively small.

(2) At low flow rates, the radial thrust for the hydraulic part increases for a blade phase angle in the vicinity of $\theta_{0}=180^{\circ}$ and decreases in the vicinity of $\theta_{0}=$ $0^{\circ}$. These tendencies are more significant in impellers with larger blade outlet angles. On the contrary, for high flow rates, the radial thrust for the hydraulic part increases in the vicinity of $\theta_{0}=0^{\circ}$ and is largest in impellers with large blade outlet angles. Conversely, the radial thrust for the hydraulic part decreases in the vicinity of $\theta_{0}=180^{\circ}$ and is smallest in impellers with small blade outlet angles.
(3) For the time-averaged value of the axial thrust for the rear and front shroud parts, the absolute value gets larger for impellers with large blade outlet angles at high flow rates. Therefore, for the time-averaged value of the total axial thrust, the absolute value is largest for the impeller with a blade outlet angle of $24^{\circ}$, but hardly any difference is seen between the impellers of $8^{\circ}$ and $16^{\circ}$.

(4) The absolute value of the axial thrust for the rear and front shroud parts is largest, for low flow rates, in the vicinity of $\theta_{0}=90^{\circ}-180^{\circ}$ and for high flow rates, in the vicinity of $\theta_{0}=0^{\circ}$. This is because the leakage flow rate increases with an increase in the static pressure around the impeller, so that a high pressure acts on the outer surface of the rear and front shrouds and there is a greater tendency for this to occur in impellers with large blade outlet angles. 


\section{Nomenclature}

\author{
$b$ : $\quad$ Blade width $(\mathrm{m})$ \\ $C_{P}$ : Pressure coefficient $=\left(P-P_{s}\right) /\left(\rho u_{2}^{2} / 2\right)$ \\ $C_{q}$ : Leakage flow rate coefficient $=q /\left(2 \pi r_{2}^{2} u_{2}\right)$ \\ $D$ : Impeller diameter $(\mathrm{m})$ \\ $f_{a}$ : Axial thrust coefficient $=F_{a} /\left(\rho u_{2}^{2} \pi r_{2}^{2} / 2\right)$ \\ $f_{r}:$ Radial thrust coefficient $=F_{r} /\left(\rho u_{2}^{2} b_{2} r_{2} / 2\right)$ \\ $F_{a}:$ Axial thrust $(\mathrm{N})$ \\ $F_{r}:$ Radial thrust $(\mathrm{N})$ \\ $g:$ Gravitational acceleration $\left(\mathrm{m} / \mathrm{s}^{2}\right)$ \\ $H$ : Total head (m) \\ L: $\quad$ Shaft power (W) \\ $n: \quad$ Rotational speed $\left(\mathrm{min}^{-1}\right)$ \\ $P: \quad$ Static pressure (gauge pressure) $(\mathrm{Pa})$ \\ $q$ : Leakage flow rate $\left(\mathrm{m}^{3} / \mathrm{s}\right)$ \\ Q: Flow rate $\left(\mathrm{m}^{3} / \mathrm{s}\right)$ \\ $r$ : Impeller radius $(\mathrm{m})$ \\ $u$ : Circumferential velocity $(\mathrm{m} / \mathrm{s})$ \\ $\beta_{b}$ : Blade angle $\left(^{\circ}\right)$.
}

\section{Greek Letters}

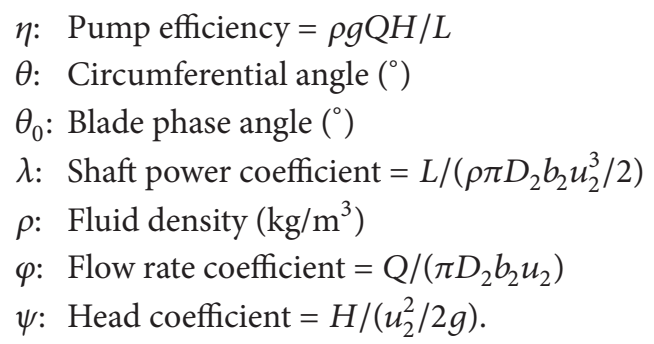

Subscripts

0: Impeller suction inlet

1: Blade inlet

2: Blade outlet

a: Axial component

$r$ : Radial component

$s$ : Suction side reference position

$x$ : $x$ component

$y: y$ component

$z: z$ component.

\section{Conflict of Interests}

The authors declare that there is no conflict of interests regarding the publication of this paper.

\section{Acknowledgment}

This work was supported by JSPS KAKENHI Grant no. 24760130 .

\section{References}

[1] Japan Institute of Wastewater Engineering Technology, Wastewater Manhole Pump Technology Manual-June 1997, 1997.

[2] Y. Yoshida, T. Sakatani, T. Kawakami, and Y. Tsujimoto, "Study of hydraulic unbalance caused by geometrical manufacturing errors of centrifugal impeller (1st Report: Experimental Results)," Turbomachinery, vol. 23, no. 2, pp. 72-77, 1995.

[3] T. Okamura, "Radial thrust in centrifugal pumps with single vane impeller," Transactions of the Japan Society of Mechanical Engineers Series B, vol. 45, no. 398, pp. 1458-1464, 1979.

[4] M. Aoki, "Instantaneous inter-blade pressure distributions and fluctuating radial thrust in a single-blade centrifugal pump," Transactions of the Japan Society of Mechanical Engineers B, vol. 50, no. 451, pp. 661-669, 1984.

[5] F.-K. Benra, H. J. Dohmen, and O. Schneider, "Calculation of hydrodynamic forces and flow induced vibrations of centrifugal sewage water pumps," in Proceedings of the 4th ASME/JSME Joint Fluids Engineering Conference, pp. 603-608, Honolulu, Hawaii, USA, July 2003.

[6] F.-K. Benra, H. J. Dohmen, and M. Sommer, "Experimental investigation of hydrodynamic forces for different configurations of single-blade centrifugal pumps," in Proceedings of the 11th International Symposium on Transport Phenomena and Dynamics of Rotating Machinery (ISROMAC '11), pp. 541-548, Honolulu, Hawaii, USA, March 2006.

[7] I. Ishida, "The consideration in the radial thrust decrease of centrifugal pump," Turbomachinery, vol. 30, no. 12, pp. 741-746, 2002.

[8] F.-K. Benra, "Numerical and experimental investigation on the flow induced oscillations of a single-blade pump impeller," Transactions of the ASME, Journal of Fluids Engineering, vol. 128, no. 4, pp. 783-793, 2006.

[9] F.-K. Benra, "Application of fluid/structure interaction methods to determine the impeller orbit curves of a centrifugal pump," in Proceedings of the 5th IASME/WSEAS International Conference on Fluid Mechanics and Aerodynamics, Athens, Greece, 2007.

[10] J. Pei, H. J. Dohmen, S. Q. Yuan, and F.-K. Benra, "Investigation of unsteady flow-induced impeller oscillations of a singleblade pump under off-design conditions," Journal of Fluids and Structures, vol. 35, pp. 89-104, 2012.

[11] Y. Nishi, R. Fujiwara, and J. Fukutomi, "Design method for single-blade centrifugal pump impeller," Journal of Fluid Science and Technology, vol. 4, no. 3, pp. 786-800, 2009.

[12] Y. Nishi, J. Fukutomi, and R. Fujiwara, "Radial thrust of single-blade centrifugal pump," International Journal of Fluid Machinery and Systems, vol. 4, no. 4, pp. 387-395, 2011.

[13] Y. Nishi, J. Fukutomi, and R. Fujiwara, "Effect of blade outlet angle on radial thrust of single-blade centrifugal pump," in Proceedings of the 26th IAHR Symposium on Hydraulic Machinery and Systems, Beijing, China, August 2012.

[14] Y. Nishi, J. Fukutomi, and M. Sakai, "Study on unsteady hydrodynamic force of closed-type centrifugal pump with singleblade," Transactions of the Japan Society of Mechanical Engineers $B$, vol. 78, no. 788, pp. 837-849, 2012.

[15] Y. Nishi, J. Fukutomi, and M. Sakai, "Component analysis of unsteady hydrodynamic force of closed-type centrifugal impeller with single-blade," Transactions of the Japan Society of Mechanical Engineers, Series B, vol. 78, no. 796, pp. 2062-2075, 2012. 
[16] K. Tanaka, M. Arai, S. Ikeo, and Y. Matsumoto, "Radial thrust in screw centrifugal pump impeller," Turbomachinery, vol. 17, no. 4, pp. 215-221, 1989.

[17] ANSYS, ANSYS CFX-Solver Modeling Guide, 2010.

[18] R. C. Worster, "The flow in volutes and its effect on centrifugal pump performance," Institution of Mechanical Engineers, vol. 177, no. 31, pp. 843-875, 1963. 

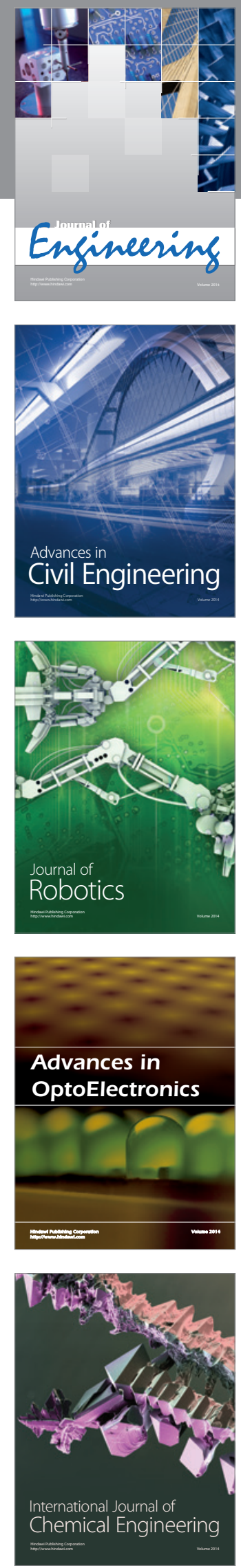

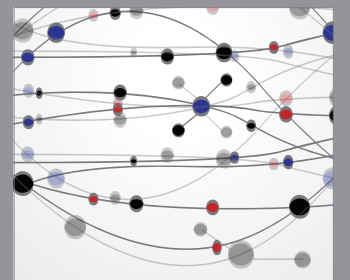

The Scientific World Journal
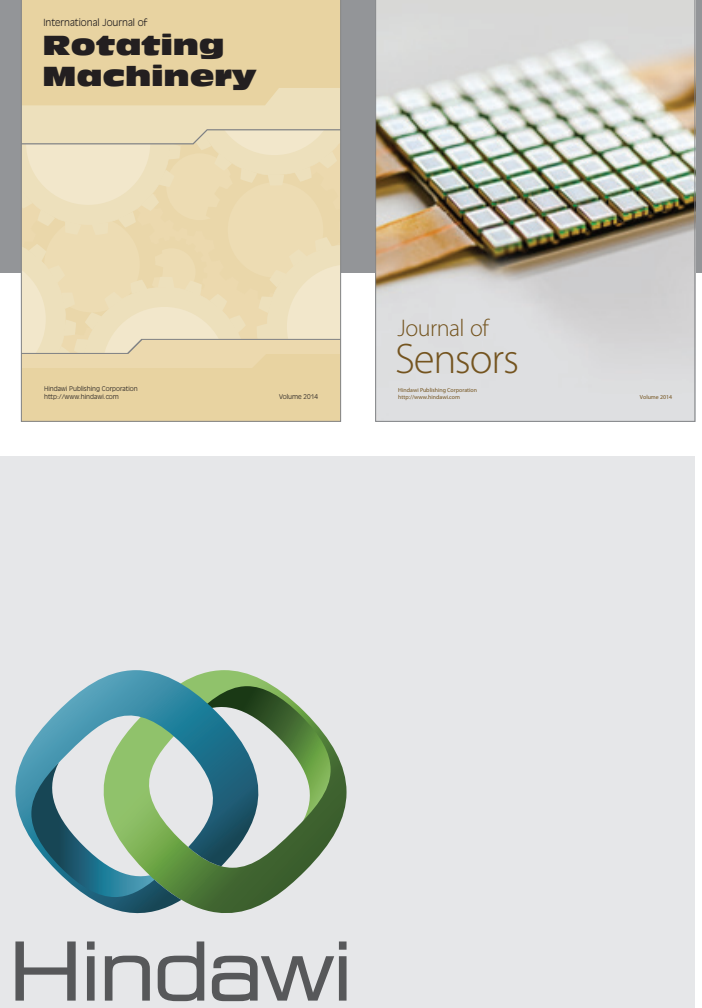

Submit your manuscripts at http://www.hindawi.com
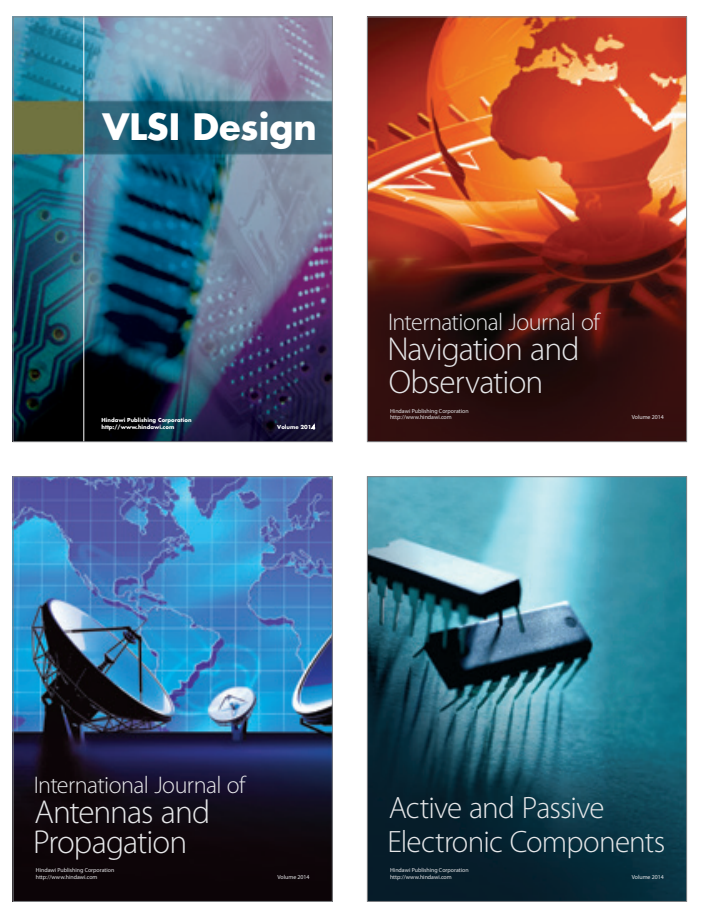
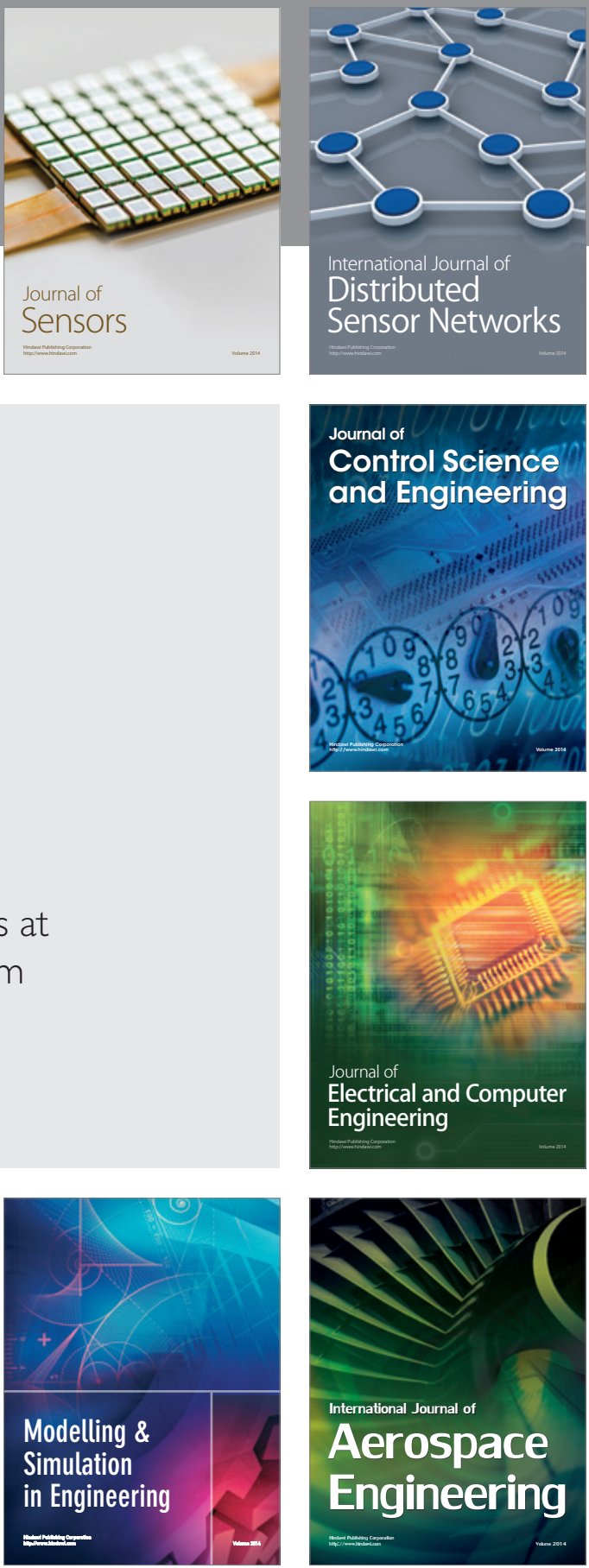

Journal of

Control Science

and Engineering
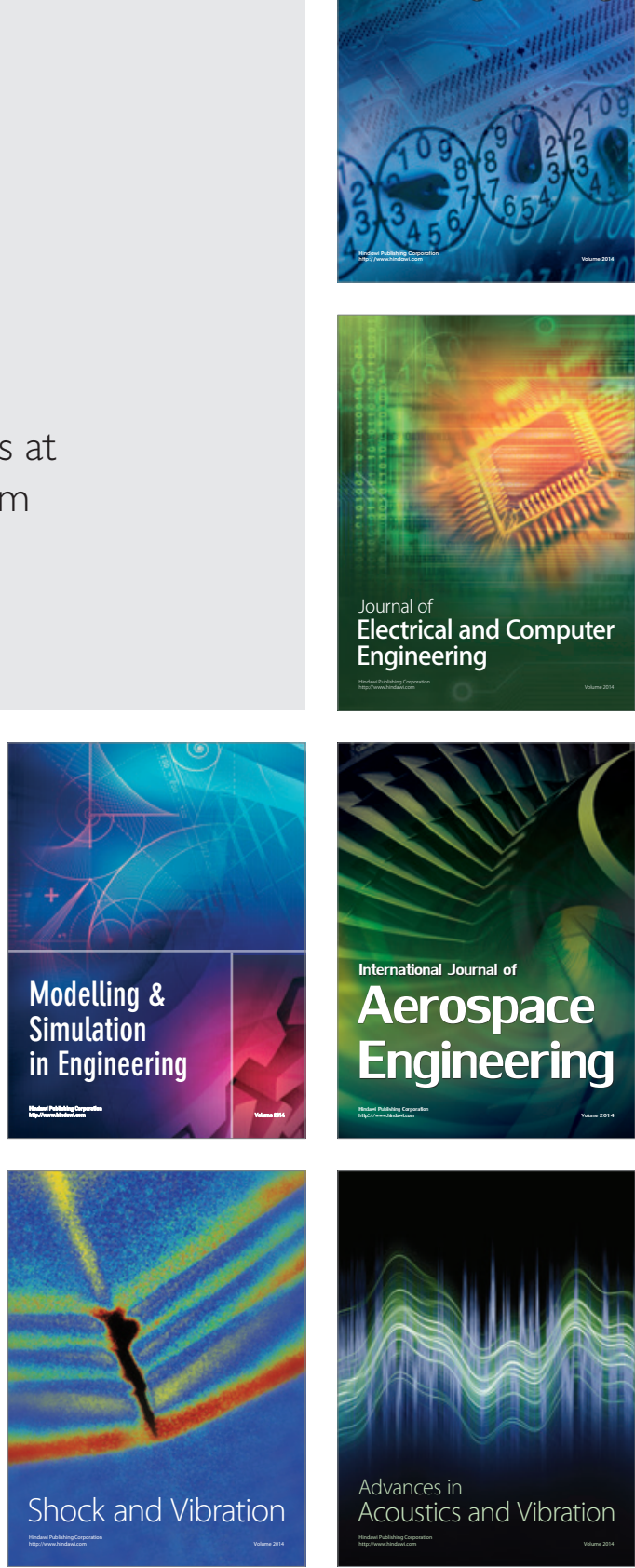